\title{
INCCA: Integrated Climate and Carbon
}

\author{
S.L. Thompson
}

March 13, 2001

U.S. Department of Energy

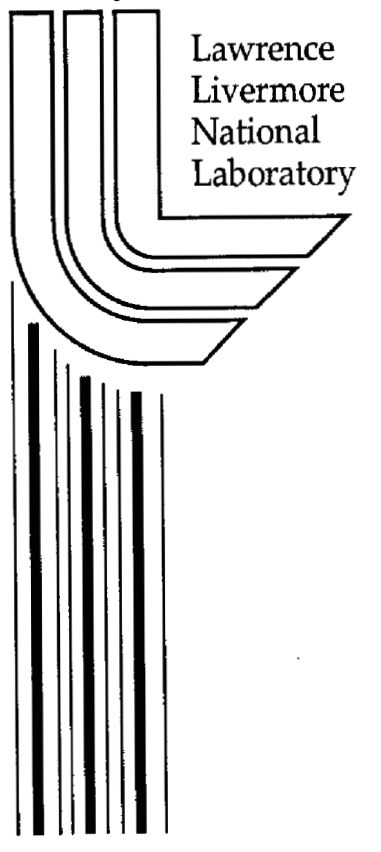




\section{DISCLAIMER}

This document was prepared as an account of work sponsored by an agency of the United States Government. Neither the United States Government nor the University of California nor any of their employees, makes any warranty, express or implied, or assumes any legal liability or responsibility for the accuracy, completeness, or usefulness of any information, apparatus, product, or process disclosed, or represents that its use would not infringe privately owned rights. Reference herein to any specific commercial product, process, or service by trade name, trademark, manufacturer, or otherwise, does not necessarily constitute or imply its endorsement, recommendation, or favoring by the United States Government or the University of California. The views and opinions of authors expressed herein do not necessarily state or reflect those of the United States Government or the University of California, and shall not be used for advertising or product endorsement purposes.

This work was performed under the auspices of the U. S. Department of Energy by the University of California, Lawrence Livermore National Laboratory under Contract No. W-7405-Eng-48.

This report has been reproduced

directly from the best available copy.

Available to DOE and DOE contractors from the

Office of Scientific and Technical Information

P.O. Box 62, Oak Ridge, TN 37831

Prices available from (423) 576-8401

http:/ /apollo.osti.gov/bridge/

Available to the public from the

National Technical Information Service

U.S. Department of Commerce 5285 Port Royal Rd., Springfield, VA 22161

http://www.ntis.gov/

OR

Lawrence Livermore National Laboratory

Technical Information Department's Digital Library

http://www.llnl.gov/tid/Library.html 


\title{
INCCA: Integrated Climate and Carbon
}

\author{
Principal Investigator: \\ Starley L. Thompson \\ Atmospheric Science Division, E\&E Directorate
}

13 March 2001

Version 2

\begin{abstract}
The INCCA (Integrated Climate and Carbon) initiative will develop and apply the ability to simulate the fate and climate impact of fossil fuel-derived carbon dioxide $\left(\mathrm{CO}_{2}\right)$ and aerosols on a global scale. Coupled climate and carbon cycle modeling like that proposed for INCCA is required to understand and predict the future environmental impacts of fossil fuel burning. At present, atmospheric $\mathrm{CO}_{2}$ concentrations are prescribed, not simulated, in large climate models. Credible simulations of the entire climate system, however, need to predict time-evolving atmospheric greenhouse forcing using anthropogenic emissions as the fundamental input.

Predicting atmospheric $\mathrm{CO}_{2}$ concentrations represents a substantial scientific advance because there are large natural sources and sinks of carbon that are likely to change as a result of climate change. Both terrestrial (e.g., vegetation on land) and oceanic components of the carbon cycle are known to be sensitive to climate change. Estimates of the amount of man-made $\mathrm{CO}_{2}$ that will accumulate in the atmosphere depend on understanding the carbon cycle. For this reason, models that use $\mathrm{CO}_{2}$ emissions, not prescribed atmospheric concentrations, as fundamental inputs are required to directly address greenhouse-related questions of interest to policymakers.
\end{abstract}

INCCA is uniquely positioned to make rapid progress in this high-priority area of global change modeling and prediction because we can leverage previous and ongoing LLNL developments, and use existing component models that are well-developed and published. The need for a vastly improved carbon dioxide prediction capability is appreciated by the DOE. As the U.S. Accelerated Climate Prediction Initiative (ACPI) progresses, we expect the DOE will emphasize the carbon cycle as the next major department-level earth science focus. INCCA will position LLNL for substantial additional funding as this new focus is realized.

In the limited time since our LDRD funding was first received (1 November 2000) we have made good progress in acquisition and testing of component models, applications of the terrestrial biosphere model, enhancements to the ocean carbon cycle model and development of the fossil fuel aerosol model. 


\section{Table of Contents}

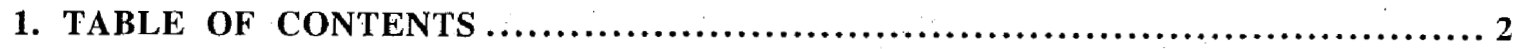

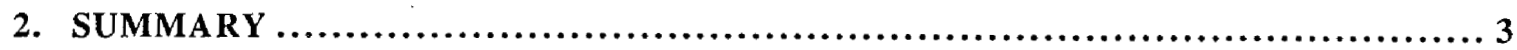

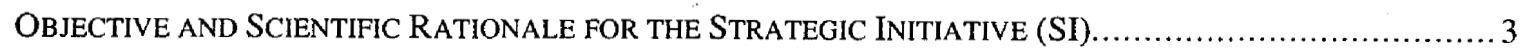

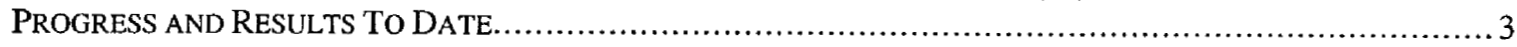

3. SCIENTIFIC AND STRATEGIC RATIONALE..............................4

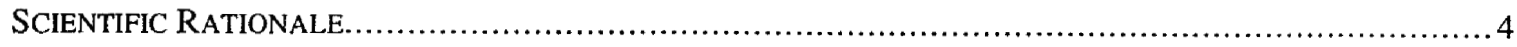

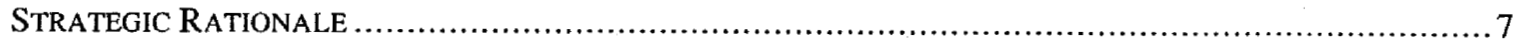

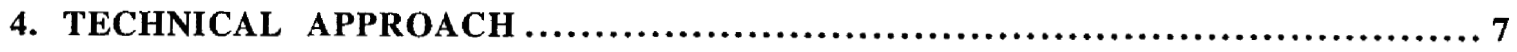

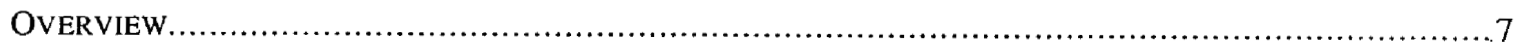

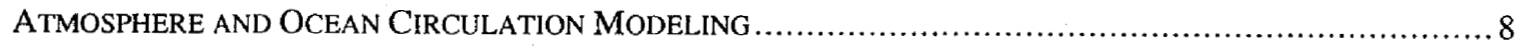

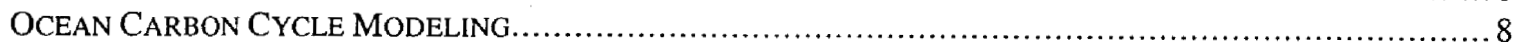

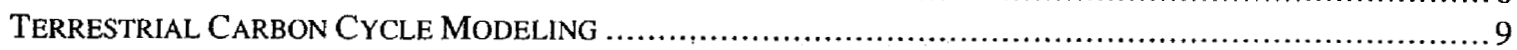

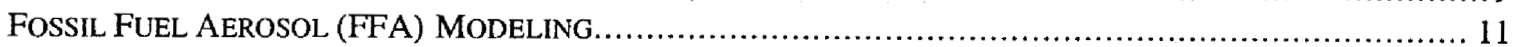

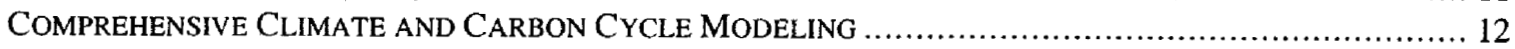

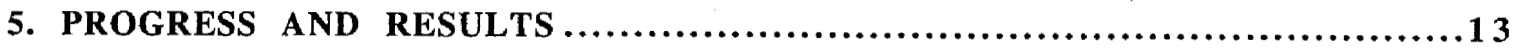

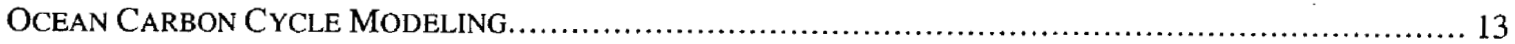

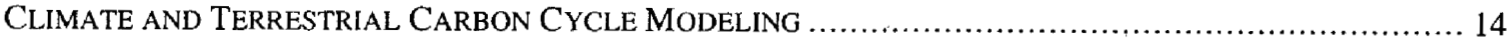

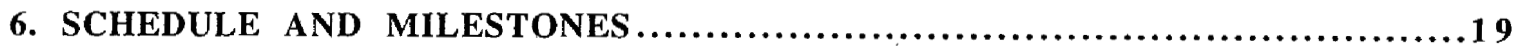

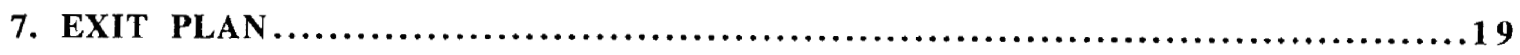

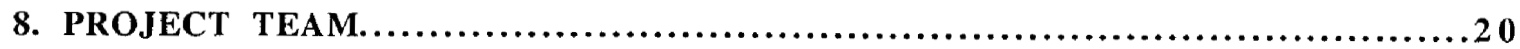

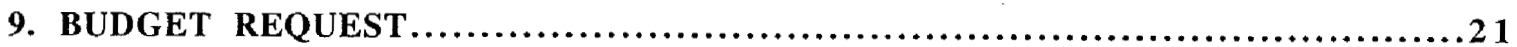

10. CAPABILITY COMPUTING REQUEST.................................2

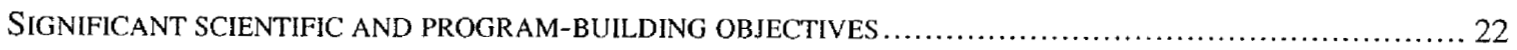

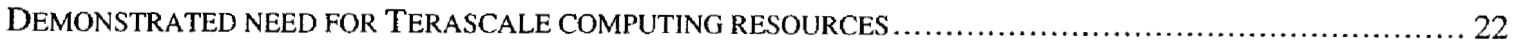

EXPERTISE IN PARALLEL COMPUTING AND ACADEMIC PARTNERS........................................... 22

11. JUSTIFICATION FOR CAPABILITY COMPUTING REQUEST................23

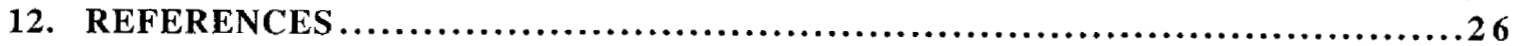

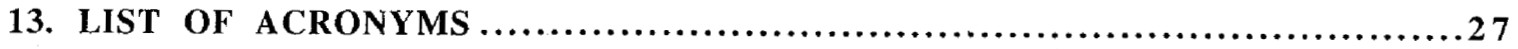

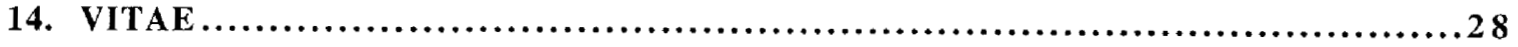




\section{Summary}

\section{Objective and Scientific Rationale for the Strategic Initiative (SI)}

The INCCA (Integrated Climate and Carbon) initiative is developing and applying the ability to simulate the fate and climate impact of fossil fuel-derived carbon dioxide $\left(\mathrm{CO}_{2}\right)$ and aerosols on a global scale. This capability will require interactive, dynamical treatments of both the terrestrial and oceanic ecological and biogeochemical components of the carbon cycle.

A U.S. Carbon Cycle Science Plan (1999) states,

"...to predict the behavior of Earth's climate system in the future, we must be able to understand the functioning of the carbon system and predict the evolution of atmospheric $\mathrm{CO}_{2}$."

Coupled climate and carbon cycle modeling like that proposed for INCCA is required to understand and predict the future environmental impacts of fossil fuel burning.

At present, atmospheric $\mathrm{CO}_{2}$ concentrations are prescribed, not simulated, in large climate models. To assess impacts of fossil fuel burning, however, we need to predict time-evolving atmospheric greenhouse forcing using anthropogenic emissions as the fundamental input. Predicting atmospheric $\mathrm{CO}_{2}$ concentrations represents a substantial scientific advance because large terrestrial biospheric and oceanic sources/sinks of carbon are key components of the present-day carbon cycle that will likely change in the future. Models driven by prescribed greenhouse gas emission rates (not concentrations) are needed to assess impacts of proposed emission policies.

\section{Progress and Results To Date}

\section{Subcontract to University of Wisconsin (UW)}

The subcontract for development and testing of the IBIS terrestrial biosphere model was finalized in January 2001.

\section{Summary of work to date}

- Good progress has been made in simulating the interannual variability of terrestrial carbon uptake using the CCM3 climate model coupled to a non-parallel version of the IBIS terrestrial biosphere model.

- Parallelization of IBIS for distributed memory computers is underway.

- Test runs are now being done with the IMPACT-FFA fossil fuel aerosol chemistry model.

- The PCM-2 coupled climate model has been acquired and we are testing approaches to reduce the run time required to reach equilibrium states.

- We have obtained an improved response to global warming with an enhanced version of our coupled ocean circulation/carbon cycle model.

- The ocean biogeochemical model has been enhanced to allow climate change experiments. 


\section{Status of exit plan}

- The LLNL INCCA effort has become a charter member of the newly formed international Coupled Climate and Carbon Cycle Model Intercomparison Project (C4MIP). This will enhance our external visibility.

- We continue to push for more attention to carbon cycle modeling in the current multilaboratory proposal being prepared in response to DOE's latest call for proposals (Scientific Discovery through Advanced Computing (SciDAC)).

\section{Scientific and Strategic Rationale}

\section{Scientific Rationale}

One of the fundamental scientific research problems of the current age concerns the degree to which human activities may alter global climate (Houghton, et al 1996). The principal source of potential climate change is the radiatively active "greenhouse" gas carbon dioxide $\left(\mathrm{CO}_{2}\right)$ produced from burning fossil fuels. There are other man-made and man-influenced greenhouse gases (e.g., methane, nitrous oxide, ozone), but $\mathrm{CO}_{2}$ has the largest overall effect and is expected to dominate future climate change.

In addition to the warming effect of $\mathrm{CO}_{2}$, the burning of fossil fuels produces aerosols that have their own radiative effects. Sulfur emissions lead to the chemical formation of sulfate aerosols that can have a regional cooling effect by reflecting sunlight. Sulfate aerosols may also increase the reflectivity of clouds by acting as surplus nuclei for cloud droplet condensation. On the other hand, sooty, elemental carbon-containing aerosols (e.g., smoke) can have a warming effect by absorbing sunlight.

Aerosol effects from fossil fuel burning are thought to be producing some significant regional scale net cooling at present. This cooling may have had some effect in "masking" the expected global warming from the increase of $\mathrm{CO}_{2}$ during the $20^{\text {th }}$ century.

Knowledge of the future concentration of atmospheric carbon dioxide is required to predict future climate change. However, at present, atmospheric $\mathrm{CO}_{2}$ concentrations are prescribed, not simulated, in large numerical climate models. The $\mathrm{CO}_{2}$ concentrations used in the simulations are taken from hypothetical scenarios, simple extrapolations, or simplified offline models. Credible simulations of the entire climate system, however, need to predict time-evolving atmospheric greenhouse forcing using anthropogenic (man made) emissions as the fundamental input.

Predicting atmospheric $\mathrm{CO}_{2}$ concentrations represents a substantial scientific advance because large land vegetation and oceanic sources/sinks of carbon are key components of the present-day carbon cycle that will likely change in the future as a result of climate change. Thus, the carbon cycle and the climate system are linked in such a way that both must be simulated simultaneously in order to produce credible predictions of future climate change.

At present, humans introduce about 6 petagrams (or gigatons) of fossil fuel-derived carbon into the atmosphere each year in the form of carbon dioxide. This and previous emissions have resulted in an increase in concentration of atmospheric $\mathrm{CO}_{2}$ from about 280 parts per million (ppmv) during the mid $19^{\text {th }}$ century to about $370 \mathrm{ppmv}$ today. The atmospheric concentration is expected to continue to increase until it levels off at some "stabilization value" depending on governmental agreements to control emissions. 
However, not all anthropogenic $\mathrm{CO}_{2}$ stays in the atmosphere. Only about half of the emissions accumulate, the so-called "airborne fraction". The rest is taken up by the oceans or vegetation/soils as part of the carbon cycle. These carbon cycle sinks of carbon dioxide are expected to change as climate changes.

The terrestrial (mostly plants) and marine (ocean circulation; chemistry and biology) components of the global carbon cycle transfer large amounts of $\mathrm{CO}_{2}$ into and out of the atmosphere seasonally and geographically. Thus, the net transfer of carbon that occurs, about half the man-made input, is small compared to the large gross fluxes of the system. This makes simulation a challenge, but more importantly, it helps produce a system that is delicately balanced and sensitive to climate change.

The uptake of carbon dioxide by the oceans occurs primarily in a few regional areas of the high latitudes of the northern and southern hemispheres (see Fig. 1B). These areas are thought to be susceptible to large changes in ocean circulation that could arise from global warming. This concern is based on model simulations and observations from the geologic record of past climate changes.

The long-term uptake of carbon dioxide by land plants can also be perturbed by changes in climate. Recent simulations have shown that interannual variations in rainfall during the past few decades probably resulted in large changes in net carbon uptake by the land biosphere. Even the sign of the uptake can vary from year to year. In a globally warmed future, the response of the land biosphere is uncertain, but it has the potential to play a large role in determining how much $\mathrm{CO}_{2}$ remains in the atmosphere. Added to this is the uncertain direct effect of extra $\mathrm{CO}_{2}$ on plant growth, the so-called "fertilization" effect.

It is important to emphasize that none of these interactive effects of climate change on the ocean and land components of the carbon cycle is included in today's comprehensive climate model projections of future climate. Simply put, today's models do not predict $\mathrm{CO}_{2}$. Instead, they have it prescribed. This weakness must be addressed in order to develop credible predictions of future climate change.

The key science questions that INCCA will address are:

- How might the ocean carbon sink change because of future climate change?

- How might the land carbon sink change because of future climate change?

- Will fossil fuel-derived aerosols (FFAs) remain a significant climate impact in the future? 

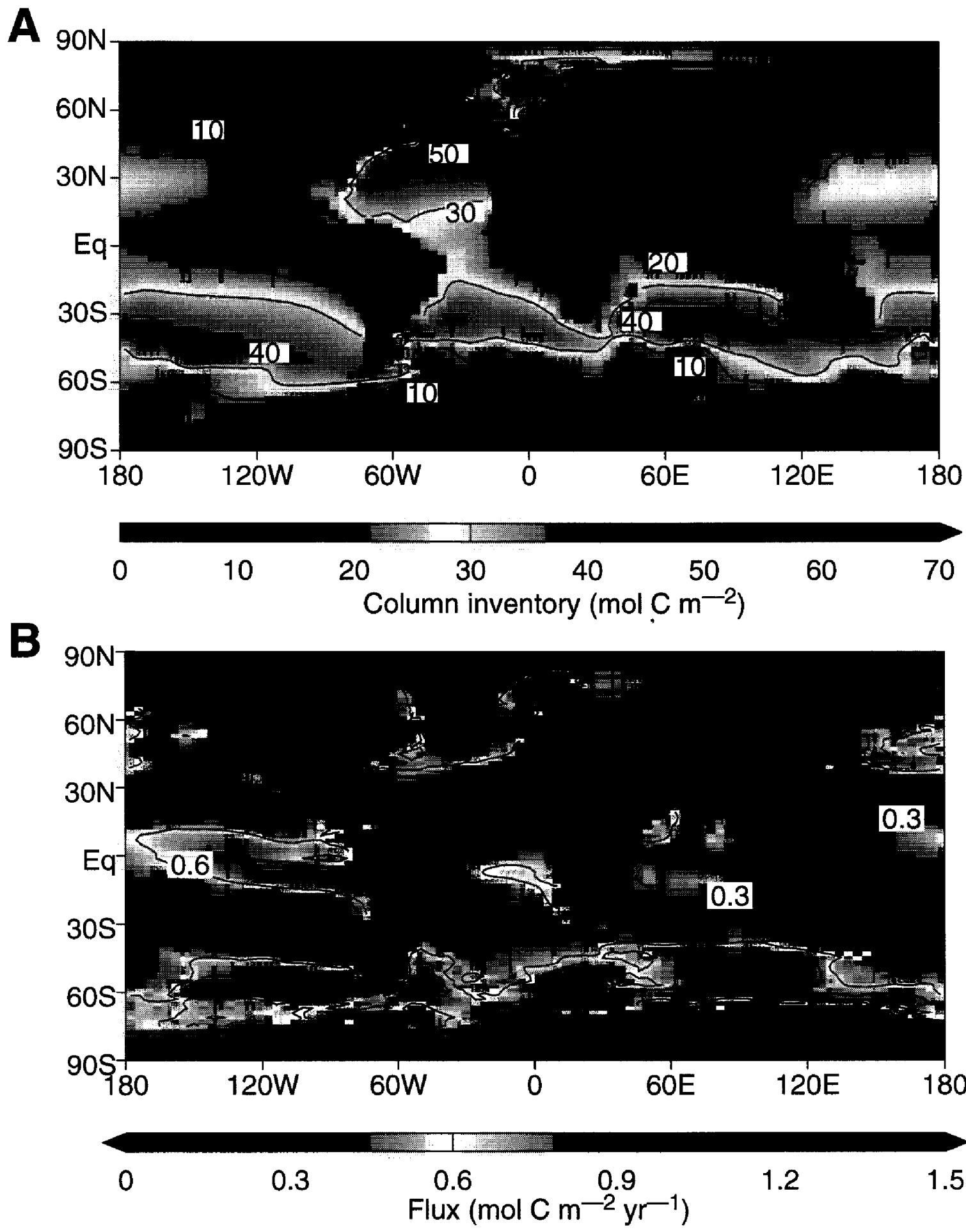

Figure 1. (A) Column inventories and (B) fluxes of anthropogenic carbon as of 1995, as simulated by the LLNL Ocean Carbon Cycle Model. The uptake of carbon by the ocean in small regions at high latitudes can be seen in B. Ocean circulation moves this carbon so that the largest column abundances $(A)$ don't occur where fluxes are largest. 


\section{Strategic Rationale}

This project is

- Using fully-coupled state-of-the-art models to address for the first time the critical scientific questions associated with climate change:

- How will climate change affect the efficiency of the ocean at absorbing fossilfuel carbon?

- How will climate-induced changes in terrestrial ecosystems affect the ability of plants to absorb fossil-fuel carbon (e.g., how important is the carbon dioxide fertilization effect)?

- Providing improved scientific understanding needed to formulate US energy policy. To directly answer policy-related questions, we need to be able to predict the climatic consequences of proposed "emissions scenarios" (rates of future fossil fuel burning). This will allow us to evaluate, for example, the climatic influence of proposed reductions in fossil fuel burning or proposed oceanic or geologic "sequestration" of fossil-fuel carbon. This is impossible at present with all but the simplest models, because today's climate models use atmospheric $\mathrm{CO}_{2}$ concentrations, not rates of fossil fuel burning, as their fundamental input. INCCA will thus provide the first state-of-the-art climate models capable of directly addressing this type of policy-related question.

- Contributing to the science base behind international treaties designed to limit global warming and to which the US is a party. These treaties have tremendous political and economic importance. Thus, the activities we propose are important and are appropriate for a national laboratory.

- Furthering LLNL's leadership in environmental simulation by building on our existing expertise in atmospheric science and computational physics.

- Positioning LLNL to obtain significantly increased DOE funding as the focus of DOE climate funding shifts toward carbon cycle issues.

\section{Technical Approach}

\section{Overview}

Our approach relies on the use of existing models that are well developed and published. In only a few instances (noted below) is it necessary to develop new codes for INCCA, and even then the development will rely on a strong foundation of existing work. This approach is possible because we are building on previous efforts at LLNL and elsewhere in climate modeling and scientific computing.

Comprehensive and credible modeling of the interactions of the carbon cycle and climate requires models of atmosphere and ocean circulation, the terrestrial (land) carbon cycle, 
the ocean carbon cycle, and fossil fuel-derived aerosols (FFAs). Each of these components is discussed briefly below. The reader should also consult Section 11 (Justification for Capability Computing Request) for computational information categorized by the science objectives of each modeling subset.

Since we are making use of existing models, some of which were largely developed elsewhere; it is legitimate to ask what makes INCCA unique and competitive in its approach. We believe:

- No other institution has both the on-site science expertise and access to world-class terascale computing power necessary to allow an effort like INCCA to succeed.

- INCCA will produce breakthroughs in science applications by making use of proven existing models and by running at optimal spatial resolution. By performing simulations at optimal grid resolutions, we can enhance throughput on real science and policy problems.

\section{Atmosphere and Ocean Circulation Modeling}

This activity is well developed here at LLNL. At present we are using the emerging de facto national standard climate modeling system developed at the National Center for Atmospheric Research (NCAR) in collaboration with other national labs, including LLNL, in association with an extensive university user community. The Community Climate Model Version 3 (CCM3) will be used as the atmospheric circulation modeling component in INCCA. This will be replaced by CCM4 when that version becomes available. CCM3 is run routinely now at LLNL.

The ocean circulation model we will use is a version of the Parallel Ocean Program (POP) developed at the Los Alamos National Laboratory (LANL). Both POP, CCM3 and a coupled POP-CCM3 model system called PCM-2 (Parallel Climate Model version 2) that was developed by Dr. Warren Washington at NCAR, are running currently at LLNL. A future, as yet-unnamed, climate model that will couple CCM4 with an enhanced version of POP is now being developed within the USGCRP community (including at LLNL). INCCA will adopt this model when it becomes available.

Model use and science objectives: The atmosphere and ocean circulation models are the foundation components of INCCA. These components are ready now and will be replaced by updated models when they become available as part of ongoing work not part of this proposal.

\section{Ocean Carbon Cycle Modeling}

INCCA is using the ocean carbon cycle model that has been developed within the Climate and Carbon Cycle Modeling Group of ASD by Co-I Ken Caldeira and his coliaborators. This model performs among the best of those considered by the Ocean Carbon-cycle Model Intercomparison Project, particularly in the Southern Hemisphere. The simulation of anthropogenic carbon dioxide (Caldeira and Duffy, 2000) is among the first to be largely consistent with observations (Fig. 1). A large part of the reason for Caldeira and Duffy's improved realism is the enhanced treatment of the coupling of sea-ice and ocean models (Duffy and Caldeira, 1997). This model is now being improved in collaboration with Paul Falkowski (Rutgers), Kenneth Coale (MLML), Sallie Chisholm (MIT), Jim Bishop (Lawrence 
Berkeley National Laboratory, LBNL) and others, under funding from the DOE Center for Research on Ocean Carbon Sequestration (DOCS) Co-investigator Ken Caldeira is codirector of DOCS (along with Jim Bishop of LBNL), and has primarily responsibility for designing and conducting numerical simulations of ocean carbon sequestration strategies.

Model use and science objectives: The LLNL Ocean Carbon Cycle Model has been coupled to both the POP and LLNL-MOM ocean models. This LLNL-MOM version is being tested now and will be used for experiments testing the sensitivity of ocean carbon cycle to hypothetical climate changes. The LLNL Ocean Carbon Cycle Model will then be coupled to the PCM-2 climate model (which uses POP as its ocean circulation model) for studies of the effects of future climate change on the oceanic uptake of anthropogenic carbon dioxide.

\section{Terrestrial Carbon Cycle Modeling}

The terrestrial model component of INCCA is IBIS (Integrated Biosphere Simulator) that has been developed by Prof: Jonathan Foley and his team at the University of Wisconsin (Foley et al., 1996; Kucharik et al., 2000). IBIS describes the physical, physiological and ecological processes occurring in vegetation and soils in a coherent, mechanistic and simple way (Figure 2).

$\mathrm{IBIS}$ reconciles the disparity among previous models by representing the following processes in a single, physically-consistent framework: (a) land surface biophysical processes; (b) ecosystem physiology and carbon balance processes (Foley, 1995); (c) vegetation phenology (e.g., seasonal effects); (d) time-dependent plant growth and competition, and (e) nutrient cycling and soil biogeochemistry.

IBIS has been validated in stand-alone mode with in-situ measurements from very different environments: a tropical forest, a mid-latitude pasture, a boreal forest, a prairie and a soybean crop (Delire and Foley, 1999). Its surface water balance has also been validated over the continental United States (Lenters et al., 2000). The model has also been tested with a wide range of continental- and global-scale data, including measurements of river discharge, net primary production, vegetation structure, root biomass, soil carbon, litter carbon, and soil $\mathrm{CO}_{2}$ flux (Kucharik et al., 2000). The ability of $|B| S$ to simulate short and long time scale processes and carbon cycling in both vegetation and soils makes IBIS an excellent tool for use within a coupled climate and carbon cycle modeling system. 


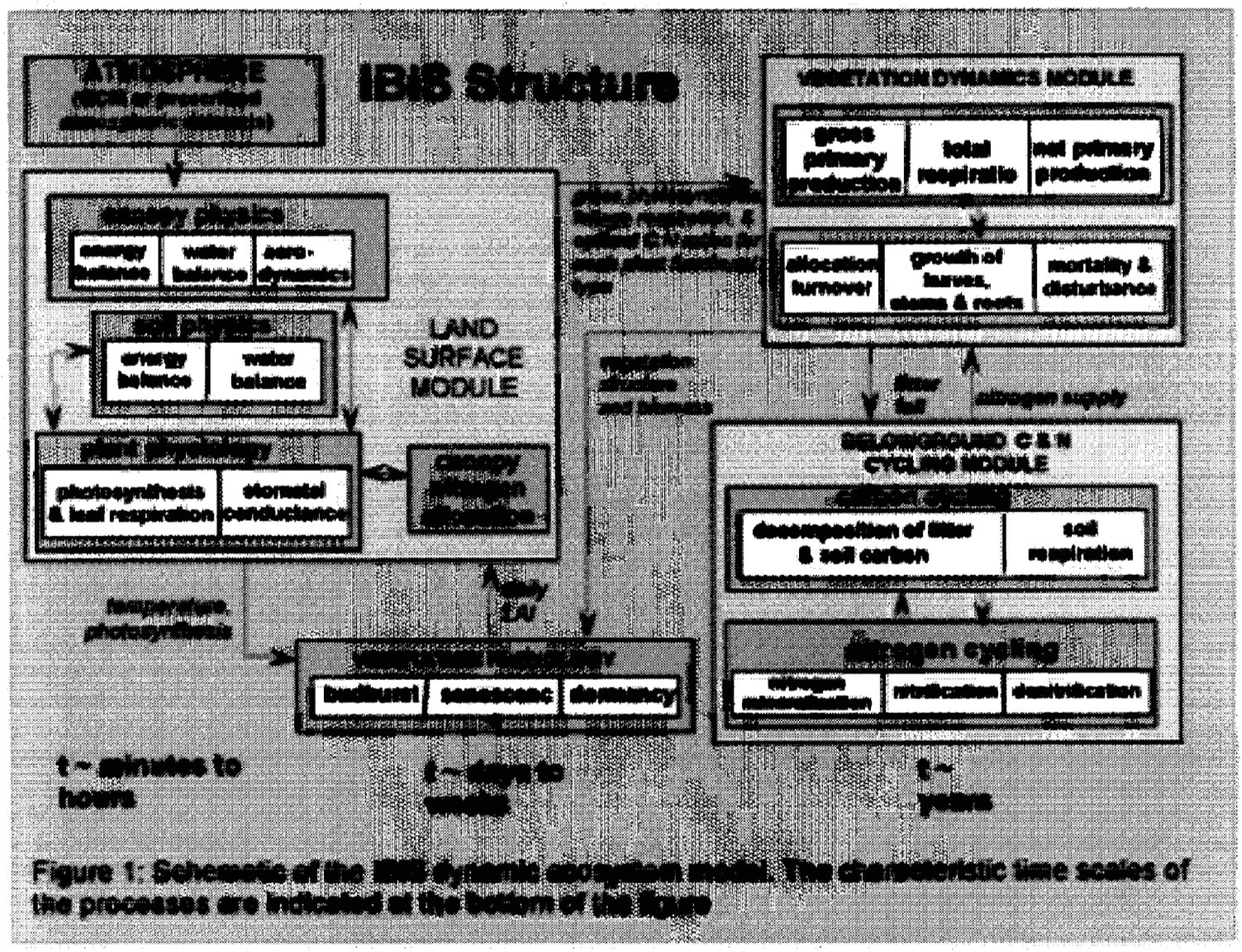

Figure 2. Schematic of the IBIS dynamic ecosystem model. The characteristic time scales of the processes are indicated at the bottom of the figure. 
The development of IBIS yielded two important landmarks in vegetation modeling:

- IBIS was the first published dynamic global vegetation model that could be used to simulate transient changes in ecosystem processes, vegetation cover, and carbon cycle effects in response to climate and land use change.

- IBIS was the first time-dependent ecosystem model to be incorporated within atmospheric general circulation models. While at NCAR, Thompson, the INCCA PI, worked with Foley to incorporate IBIS into the GENESIS earth system model (Foley et al., 1998, Thompson and Pollard, 1995). IBIS now runs interactively with a version of the NCAR CCM atmospheric general circulation model.

Model use and science objectives: The IBIS model is currently being run while coupled to the CCM3 climate model to examine how climate changes can affect carbon uptake by the terrestrial biosphere (see section 5 for more detail). After this, IBIS will be coupled to the PCM-2 model for future projections.

\section{Fossil Fuel Aerosol (FFA) Modeling}

In recent assessments of climate forcing, the Intergovernmental Panel on Climate Change (IPCC) lists aerosol as one of the most important anthropogenic agents that tend to influence the climate and atmosphere (Houghton et al, 1996). Atmospheric aerosol particles derived from fuel combustion, referred to here as "fossil fuel aerosols". (FFAs), affect the Earth's radiative balance directly by scattering or absorbing light, and indirectly by acting as cloud condensation nuclei, thereby influencing the albedo and life-time of clouds. More recently, sooty aerosols have been implicated as a possibly significant warming agent.

Accurately quantifying the direct and indirect effect of anthropogenic aerosols on the radiative forcing of climate will require determining the chemical, physical, and radiative properties of the major aerosol types, the relationships among these properties and the processes controlling them.

Here at LLNL, earlier studies have focused on developing an understanding of global sulfate and carbonaceous (sooty) aerosol abundances and investigating their climate effects. LLNL research has been recognized as an important effort in quantifying the direct and indirect (cloud) effects of anthropogenic aerosols on climate in the 1994 and 1995 IPCC report and in the pending IPCC report for 2000. (e.g., Chuang, et al., 1999).

The IMPACT (Integrated Massively Parallel Atmospheric Chemical Transport) Chemical Transport Model developed in the Atmospheric Science Division at LLNL has been coupled to a state-of-the-art microphysics model to provide the capability to simulate chemical, physical and microphysical aerosol processes. This includes emissions of precursors, chemical transformations, evolution, coagulation, cloud processes and deposition. In addition; the IMPACT model is currently being coupled to the CCM3 atmospheric circulation model (under separate funding) to provide a predictive tool for calculating radiative forcing by aerosols.

The IMPACT model is a global, three-dimensional chemistry-transport-deposition model that contains both a prognostic troposphere and stratosphere. It uses as input meteorological fields from either a General Circulation model (GCM) or data assimilated 
meteorological fields (Rotman et al., 1993). IMPACT has been successfully ported to both the Cray T3E at NERSC and the tc2k machine here at LLNL.

Model use and science objectives: Our plan is to produce an INCCA version of IMPACT (IMPACT-FFA) that is efficient enough to run coupled to our climate models. The photochemistry for this project will include a simplified sulfur chemical mechanism. If necessary, more complete chemical mechanisms exist and can be in switched quickly if needed. The IMPACT-FFA model will first be tested by coupling to a version of CCM3 having a simplified ocean. This will give us an indication of the kinds of climate effects produced by FFAs. Following that, IMPACT-FFA will be coupled to the PCM-2 model for future projections.

\section{Comprehensive Climate and Carbon Cycle Modeling}

By the end of FY 03, the INCCA initiative expects to be running a fully comprehensive integrated climate and carbon cycle model, the INCCA Fully-Coupled System Version 1, or IFS v.1. This system is expected to evolve in a straightforward manner from the use and limited coupling of its individual components performed in FY 01-02. Thus the IFS v.1 will include the PCM-2 atmosphere-ocean model (or its successor), the IBIS land biosphere model, the LLNL Ocean Carbon Cycle Model, and the IMPACT-FFA aerosol chemistry model.

Model use and science objectives: IFS v. 1 will provide for the first time the capability to perform comprehensive simulations of the interactions of the carbon cycle and climate. This will open the door to meaningful predictions that can inform national policy. 


\section{Progress and Results}

The proposed milestones for FY 01 as set forth in our original SI proposal dated March 2000 were:

- Complete spinup of POP with LLNL Ocean Carbon Model

- Use coupled IBIS with CCM3 to develop a better understanding the sources and magnitude of variation in the terrestrial carbon cycle.

- Begin testing of PCM-2 with coupled LLNL Ocean Carbon Model

- Develop IMPACT-FFA fossil fuel aerosol chemistry model

Work on the POP spinup and PCM-2 testing have now been combined since the ocean component of the PCM-2 is in fact the POP model. Progress on these milestones and related work to date in FY 01 are described in the following.

\section{Ocean Carbon Cycle Modeling}

\section{Testing of PCM-2}

We acquired the PCM-2 coupled atmosphere ocean climate model from NCAR. Co-I Milovich is currently testing the code on the TeraCluster2000 (tc2k) computer here at LLNL. We are trying several acceleration schemes that can substantially reduce the model run time to equilibrium. Such a reduction of run time will be necessary when the ocean carbon cycle model is coupled in.

\section{Improved Parameterization in Ocean Carbon Cycle Model}

Co-ls Ken Caldeira and Phil Duffy, assisted by Mike Wickett (CASC), added a new vertical mixing scheme for tracers on momentum, where vertical mixing is inversely proportional to the vertical density gradient. This new formulation can respond to changes in stratification expected with climate change in intuitively and theoretically justifiable ways. Free parameters were tuned to provide good results for present-day radiocarbon, salinity and temperature.

\section{Enhancements for Climate Change Runs Using the Ocean Carbon Cycle Model}

Co-ls Ken Caldeira and Phil Duffy, assisted by Mike Wickett (CASC), have designed and coded a surface boundary condition which should allow us to realistically represent effects of increased atmospheric $\mathrm{CO}_{2}$ in ocean-only simulations. These effects will be represented as a prescribed perturbation to the fluxes obtained under present-day forcing. We will then perform and analyze a series of simulations describing the effects of increasing atmospheric $\mathrm{CO}_{2}$ on the ocean (particularly its behavior as a sink of atmospheric carbon). Increasing atmospheric $\mathrm{CO}_{2}$ will affect both the heat and freshwater fluxes between the ocean and atmosphere. In our simulations, we can isolate the effects of each of these by allowing one to vary while holding the other fixed. 


\section{Climate and Terrestrial Carbon Cycle Modeling}

\section{Understanding Interannual Variability in the Terrestrial Carbon Cycle}

One of the scientific goals of this $\mathrm{SI}$ is to understand the observational fact that the net flux of carbon into and out of the land biosphere is subject to interannual variability arising from climate variability. We are investigating this phenomenon using the IBIS land biosphere model coupled to the CCM3 atmospheric climate model.

We obtained the IBIS land biosphere model from our University of Wisconsin collaborators. Since the ready-to-use version of the model was not parallelized, we ported first to the CRAY J90. There it was coupled to the CCM3.6.6 atmospheric model. We performed two simulations: 1) Climatological simulation forced by time-averaged seasonal sea surface temperatures (SST). 2) A simulation forced by observed sea surface temperatures for 1979-1992.

The results from this exercise were presented at the American Geophysical Union annual meeting in December (Thompson and Govindasamy, 2000). To summarize,

- Simulations "forced" with climatological (the same from year to year) and yearlyvarying sea surface temperatures (SSTs) both produce levels of interannual variability in net terrestrial carbon uptake that are comparable to observations. This indicates that year-to-year variability produced by the atmosphere alone plays a large role in determining the variability of terrestrial carbon uptake.

- Terrestrial carbon uptake in the observed SST simulation has only a weak positive correlation with the observed uptake. This would be expected given that our model does not include variability from ocean carbon uptake, but does include the "random" noise of atmospheric variability. Both sources of variability are comparable to the variability forced by varying SSTs and thus tend to swamp the SST signal.

- The interannual variability in the terrestrial carbon uptake appears to originate from interannual precipitation and surface temperature variability as shown in Figure 3 (from Thompson and Govindasamy, 2000) 


\section{Correlation coefficient}

a) Net Carbon flux and precip.

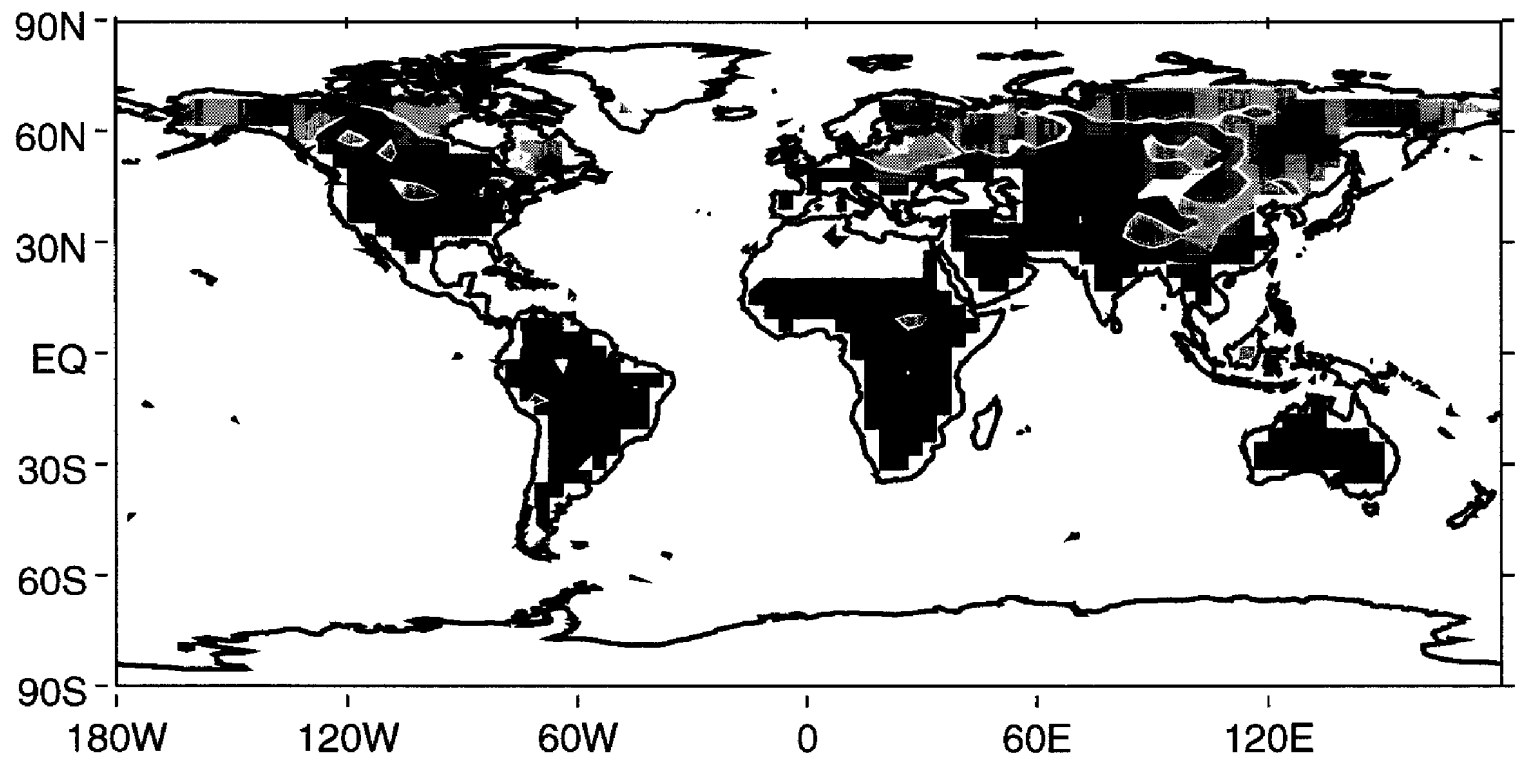

b) Net Carbon flux and surface temp.

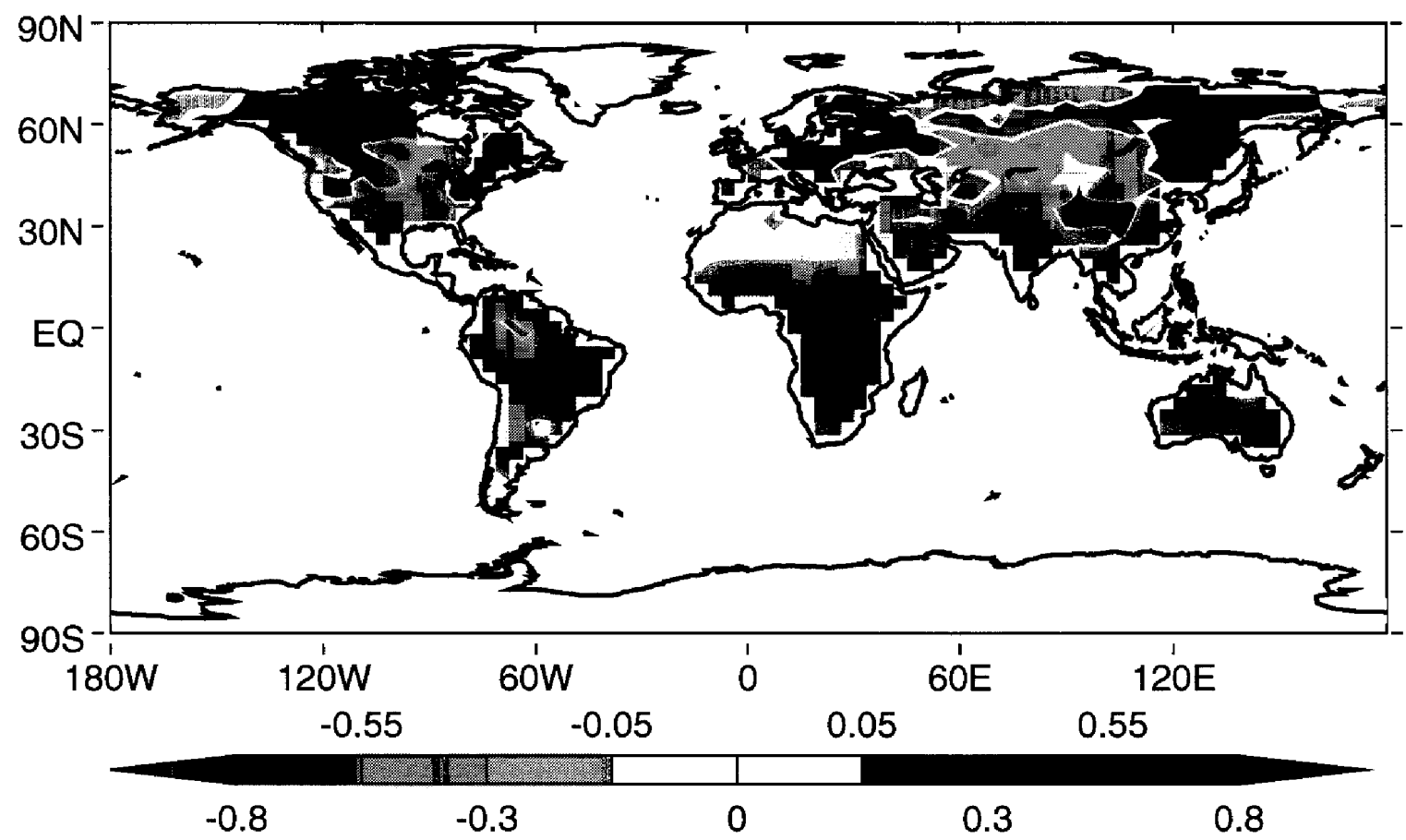

Figure 3. Correlation coefficient between net terrestrial carbon fluxes and precipitation and surface temperature. Terrestrial carbon flux has positive correlation with precipiation in lowmid latitudes and positive correlation with temperature in high latitudes (Thompson and Govindasamy, 2000). This pattern arises because precipitation tends to be the limiting factor on vegetation in warm regions, while temperature is limiting in cold regions. 
The positive correlation in the terrestrial carbon uptake between our observed SST. simulation and observations is weak. This may be due to the large interannual "noise" caused by normal interannual climate variability. We are currently analyzing an ensemble of 14 observed SST simulations so that we can meaningfully address the statistical significance of our result.

\section{Parallelization of IBIS for Distributed Memory Computers}

One of this year's tasks is to modify the IBIS land biosphere model to run efficiently on distributed memory massively parallel processor (MPP) machines. Planning for this work started in December with a visit to LLNL by Co-I Christine Delire who is a developer of IBIS at the University of Wisconsin. Co-I Govindasamy then ported a standard version of IBIS to an IBM SP where he coupled it to CCM3.10.11, the version of CCM3 that is designed for IBM and COMPAQ MPP computers. Co-I Mirin is now doing the parallelization work.

\section{IBIS Experiments at the University of Wisconsin}

The Co-Is at the University of Wisconsin (UW) are tasked primarily with developing IBIS and performing experiments to validate the model and test its sensitivity to various forcings. The subcontract from LLNL to UW to perform this work was set in place in January 2001 and thus has been in effect a limited time.

Recent work by the UW team includes the completion of a 250-year spinup to equilibrate a coupled CCM3-IBIS present-day simulation using dynamic vegetation and carbon cycling. After 250 years, the model is almost in equilibrium: soil carbon pool varies by $0.01 \%$ a year and the phytomass by $0.07 \%$. The simulated global carbon pools (vegetation and soils) and fluxes (net primary productivity, litterfall, and litter and soil carbon decomposition) are in good agreement with the NOAA estimated values for 1980 to 1989 (Table 1). The ending point of this run will provide the initial conditions for future climate change runs.

Table 1. Comparison of equilibrated CCM3-IBIS to NOAA observational estimates.

Table 1a. Fluxes in petagrams of carbon per year

\begin{tabular}{llllll} 
& assimilation & respiration & disturbance & litterfall & leaching \\
\hline \multirow{2}{*}{ NOAA } & 102 & 100 & 1.9 & 50 & 0.6 \\
CCM3-HBS & 108 & 102 & 6 & 47 & 0.3 \\
\hline
\end{tabular}

Table 1b. Pools in petagrams of carbon

\begin{tabular}{lll} 
& phytomass & Soil carbon \\
\hline NOAA & 550 & 1500 \\
CM3-IBIS & 608 & 1502 \\
\hline
\end{tabular}


Figure 4 presents the net primary productivity simulated by CCM3-IBIS averaged over the last 20 years compared to observations compiled by Gower (personal communication) and a simulation using IBIS forced with observed atmospheric data (Kucharik et al., 2000). Net primary productivity is defined as the carbon fixed by photosynthesis minus the carbon lost by aboveground plant respiration. The model captures well the latitudinal distribution of productivity. The highest values are along the equator at around $0.6 \mathrm{~kg} \mathrm{~m}^{-2}$ $\mathrm{yr}^{-1}$ in mid latitudes with lower values in the boreal regions. The biases in the precipitation field simulated by the CCM3 explain the unrealistic values of productivity in Uruguay, Burma, India and Saudi Arabia. The average net primary productivity and soil carbon content per vegetation type simulated by CCM3-IBIS compare well with the observed values.

Finally, to get a better understanding of the role that certain vegetation types and their location have on the global climate, the UW group did a series of six simulations with idealized land cover changes. All the simulations involved removing the land cover of particular combinations of vegetation types in order to identify the primary mechanisms at work and to quantify the magnitude of the biosphere's response on the climate system. These simulations are a prelude to future realistic simulations of global land cover and land use change and are currently being analyzed.

\section{Fossil Fuel Aerosol (FFA) Modeling}

Co-1 Dignon has developed a reduced sulfur chemical mechanism for the IMPACT-FFA model. The goal is to predict the time-varying distribution of sulfate aerosols using prescribed emissions as the fundamental input. The new mechanism includes 14 reactions to represent the sulfur cycle in the troposphere. The species treated include $\mathrm{O}_{3}, \mathrm{OH}, \mathrm{HO}_{2}, \mathrm{H}_{2} \mathrm{O}_{2}, \mathrm{SO}_{2}, \mathrm{DMS}, \mathrm{H}_{2} \mathrm{~S}$ and $\mathrm{S}^{\text {(IV) }}$ (sulfate), where $\mathrm{O}_{3}, \mathrm{OH}$, and $\mathrm{HO}_{2}$ are prescribed from full chemical simulations of IMPACT model. The $\mathrm{SO}_{2}$ and sulfate species are further divided according to whether their origin is natural or anthropogenic. Rates are adjusted to account for the diurnal variation of odd-hydrogen chemistry. Currently we are testing the reduced mechanism in comparison to a full tropospheric chemical mechanism for accuracy. Initial results of the comparison were presented at the AGU Fall 2000 Meeting (Dignon, et al. 2000)

Along with sulfate, we have been implementing additional aerosol species including black carbon, carbonaceous (smoke), dust, and seasalt aerosols into the model (Liousse, et al., 1996; Penner, et al., 1998; Chuang, et al., 1999; Dignon, 2001). Both natural and anthropogenic sources are included. 

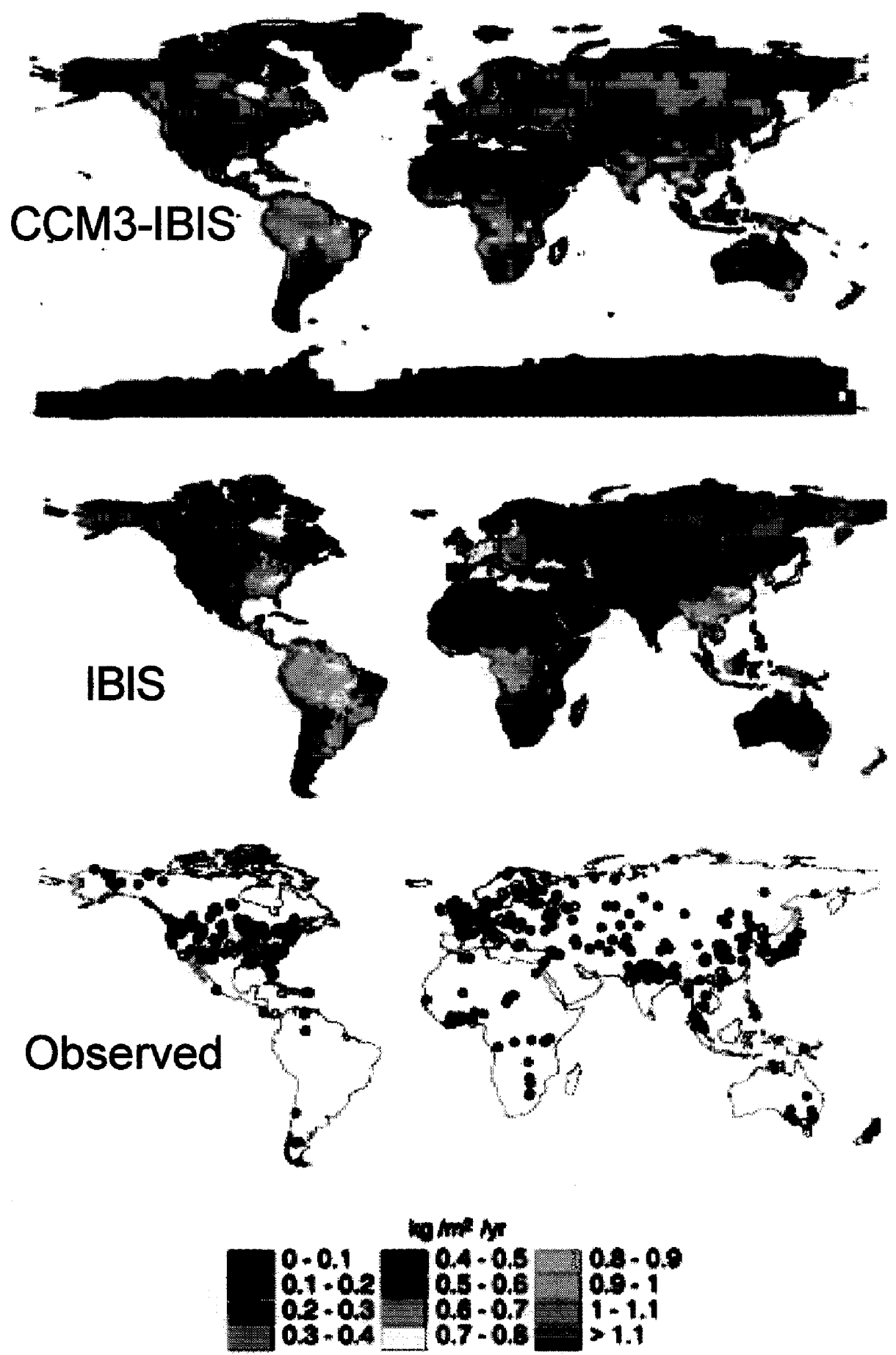

Figure 4. Net primary productivity (NPP) (a) simulated with CCM3-IBIS, (b) simulated with IBIS forced with observed atmospheric variables from the CRU05 climatology (New et al, 2000), and (c) observed (unpublished data by Gower et al.). 


\section{Schedule and Milestones}

See also Section 11 for computational information tied to science objectives. See Section 13 for definitions of acronyms. Science applications expected to lead to publications in the peer-reviewed literature are identified with $(\mathbf{P})$.

\section{$\underline{\mathrm{FY} O 2}$}

- Use coupled LLNL Ocean Carbon Model to simulate hypothetical imposed climate change scenarios. (P)

- Continue spinup of PCM-2 with coupled LLNL Ocean Carbon Model. Start performing production runs with various carbon dioxide emissions scenarios.

- Using IMPACT-FFA coupled with CCM3 to make initial estimates of the effects of fossil-fuel aerosols on climate. (P)

- Use IBIS coupled with PCM-2 to simulate possible changes in the terrestrial carbon cycle resulting from interactive climate and dynamic vegetation effects. (P)

- Start testing of coupling between IMPACT-FFA and PCM-2

- Start initial integration all component models to form the INCCA Fully-Coupled System IFS v.1.

\section{$\underline{\text { FY } 03}$}

- Finish production runs of PCM-2 and coupled LLNL Ocean Carbon Model. (P)

- Finish production runs of IBIS coupled with PCM-2. (P)Finish production runs of IMPACT-FFA coupled with PCM-2. (P)

- Complete integration of all component models to form IFS v.1. Test the system and start initial simulations.

\section{Exit Plan}

The U.S. Global Change Research Program (USGCRP) is the overarching program of the federal government that coordinates multi-agency research on global change. The USGCRP recently requested that leading scientists produce a plan for defining and prioritizing research on the carbon cycle. The result was the document $A$ U.S. Carbon Cycle Science Plan (1999). The Science Plan defines a handful of "high priorities for initial funding". All the highest priorities are related to observational issues except one: "Enhanced development of earth system modeling to include interactive carbon and climate dynamics". The Science Plan then states that $\$ 15-30$ million annually should be provided for this activity.

INCCA is designed and perfectly timed to fit this high priority requirement of the USGCRP's plan for carbon cycle and climate research.

Importantly, this need is highlighted not only by the need to resolve science questions, but also by the fact that current policy debates have out-paced the ability of science to provide crucial information. International climate policy debates (e.g., on the Kyoto agreement) now focus on carbon emission scenarios. Nevertheless, there is no adequate capability to simulate the environmental consequences of a given emissions 
scenario using our largest, most realistic models. This need for a vastly improved carbon dioxide prediction capability is appreciated by the DOE. As the U.S. Accelerated Climate Prediction Initiative (ACPI) progresses, we expect the DOE will emphasize interactions of the climate and carbon cycle as the next major earth science focus. Through INCCA, LLNL will be poised to help define and participate fully in any enhanced DOE efforts in this area is realized.

\section{Project Team}

\section{Principal Investigator}

Starley L. Thompson is a member of the Climate and Carbon Cycle Modeling Group of the Atmospheric Science Division. He is an internationally recognized authority on climate modeling, land surface processes and earth system model development. He led the GENESIS Earth System Modeling project at the National Center for Atmospheric Research before coming to LLNL in 1999.

\section{Co-Investigators}

( ${ }^{*}$ denotes foreign nationals)

Ken Caldeira is a member of the Climate and Carbon Cycle Modeling Group of the Atmospheric Science Division. He is an authority on the simulation of the oceanic component of the carbon cycle and is co-director of the DOE Ocean Carbon Sequestration Center. He is a member of the newly formed US Carbon Cycle Science Plan Interagency Advisory Committee.

Christine Delire* is a Research Associate at the Center for Sustainability and the Global Environment (SAGE) in the Institute for Environmental Studies at the University of Wisconsin. She has expertise in climate-vegetation interactions and global climate modeling.

Jane Dignon is a member of the Atmospheric Chemistry Group of the Atmospheric Science Division. She has expertise in atmospheric chemistry with particular emphasis on aerosol chemistry and emissions databases.

Philip B. Duffy is leader of the Climate and Carbon Cycle Modeling Group of the Atmospheric Science Division. He is a recognized authority on numerical modeling of ocean circulation and on climate change.

Jonathan Foley is an Associate Professor of Atmospheric \& Oceanic Sciences and Environmental Studies at the University of Wisconsin, Madison. He is an internationally recognized authority on terrestrial ecosystem and biogeochemical modeling. $\mathrm{He}$ is a member of the newly formed US Carbon Cycle Science Plan Interagency Advisory Committee.

Bala Govindasamy* is a member of the Climate and Carbon Cycle Modeling Group of the Atmospheric Science Division. He is an authority on climate modeling and use of the CCM3 climate model. 
Jose Milovich is a computational physicist at the Center for Applied Scientific Computing (CASC). He has experience with a variety of fluid dynamics models on various high performance platforms.

Arthur Mirin is a computational physicist at the Center for Applied Scientific Computing (CASC). He probably has more experience at converting climate models to run on massively parallel computers than anyone else in the world.

\section{Budget Request}

For FY 2002, the tasks and FTEs are:

Task

Effort Group

Aerosol model implementation, runs, analysis

Global model runs, analysis

0.5 FTE ASD

Terrestrial model implementation, runs, analysis

Project management and coordination

2.5 FTE ASD,CASC

1.5 FTE ASD,CASC

Total

0.7 FTE ASD

Table 2 shows the cost groupings by fiscal year.

The approximate funding distribution for $\mathrm{FY} 02$ is:

E\&E Directorate: $65 \%$, CASC: $21 \%$; Univ. of Wisconsin: $14 \%$.

Table 2. Cost groupings by fiscal year.

\begin{tabular}{|l|r|r|r|}
\hline Cost Groupings & $\mathbf{2 0 0 1}$ & $\mathbf{2 0 0 2}$ & $\mathbf{2 0 0 3}$ \\
\hline Wages & 719,342 & 793,049 & 843,804 \\
\hline Travel & 22,000 & 15,000 & 15,000 \\
\hline Procurements & 144,667 & 153,805 & 160,225 \\
\hline Service Center & 90,112 & 93,528 & 93,528 \\
\hline Total & 976,121 & $1,055,382$ & $1,112,557$ \\
\hline & & & \\
\hline Total FTE & 5.0 & 5.2 & 5.2 \\
\hline
\end{tabular}

The University of Wisconsin will receive a subcontract of approximately $\$ 140 \mathrm{~K}$ per year to develop and implement new versions of IBIS within the INCCA framework. This funding covers a month of summer salary of the INCCA Co-Investigator Jon Foley, a Ph.D.

research associate (C. Delire), some graduate student efforts, and other expenses such as travel for interactions with LLNL researchers.

In addition to financial support, we are also requesting access to LLNL capability computing resources (see Sections 10 and 11). 


\section{Capability Computing Request}

The INCCA Project is requesting access to LLNL capability computing resources at a rate of 10,000 TeraCluster CPU hours per week. This level of access is needed to satisfy the extraordinary CPU demands associated with performing coupled climate/carbon-cycle modeling using state of the art models. The memory requirements can be easily met by existing LLNL computing platforms. Likewise, storage requirements are not excessive since much of the requested allocation will be used in model spinup where data archiving is not required.

Below we describe how this project meets each of the selection criteria for access to capability computing resources. Section 11 of this proposal (Justification for Capability Computing Request) gives a more detailed description of individual scientific objectives, modeling required to reach those objectives, and the computing resources required.

\section{Significant scientific and program-building objectives}

As discussed elsewhere in this proposal, the goal of the INCCA project is to provide predictions of future climate based on prescribed rates of emission, rather than prescribed concentrations, of greenhouse gases. The distinction is critically important, in that government policies to limit global warming are formulated in terms of emission rates rather than concentrations. Thus, this project will provide the first state-of-the-art model capable of directly evaluating the climatic impacts of proposed emissions-limiting policies. Because of the urgent national need for such a capability, it is the stated goal of DOE to fund development and application of this type of model as part of its Accelerated Climate Prediction initiative Program (ACPI). By developing and demonstrating this capability using institutional resources, LLNL will position itself for substantial increased DOE climaterelated funding.

\section{Demonstrated need for Terascale computing resources}

A detailed list of the simulations we wish to perform, the models involved, and the CPU requirements for each simulation, is given in the next section. For simplicity, we have expressed our CPU requirements in terms of TeraCluster CPU hours.

\section{Expertise in Parallel Computing and Academic Partners}

The CASC/E\&E project team has more experience than any other group in the world in using massively parallel computers for climate research. This experience includes parallelization of a number of major climate models:

- UCLA atmospheric general circulation model (GCM);

- GFDL ocean GCM;

- Oberhuber sea ice model;

- SiB2 land-surface model;

- LLNL Ocean Carbon Cycle Model;

- University of Victoria energy/moisture balance atmosphere and sea ice models;

- COAMPS regional atmospheric model (in progress). 
Each of these models was parallelized using 2-dimensional domain decomposition and explicit message passing. These models have been run on nearly every recent MPP machine, including the ASCI Blue machine (although not every model has been run on every machine). Furthermore, it is important to emphasize that our experience using MPPs goes well beyond mere demonstrations, in that essentially all the simulations we have published in recent years have been run on MPPs.

Several of the models we are proposing to run under this proposal are already running on ASCl Blue. Thus, we are prepared to make immediate, substantial use of the machine.

Our academic partner is the University of Wisconsin (Professor Jonathan Foley is a CoInvestigator on this $\mathrm{SI}$ )

\section{Justification for Capability Computing Request}

Each major scientific objective of this renewal proposal is addressed below in terms of the modeling system subset required, the simulations to be performed, and the model CPU requirements (CPU hours per model simulated year). The final estimated requirements are given in TeraCluster CPU hours for each fiscal year. See Section 13 for definitions of the model acronyms. (Note: $500 \mathrm{~K}$ hours/year equals $10 \mathrm{~K}$ hours/week.)

\section{- Develop a better understanding of the response of the ocean carbon sink to possible changes in climate forcing.}

Model System Subset: LLNL Ocean Circulation and Ocean Carbon Cycle Model Resolution and Forcing: 3 degree ocean, prescribed air temperature and precipitation Status and Ready Date: In process now TeraCluster CPU hrs per sim year: 4

Runs (total length in years):

- Testing, De-bugging, Tuning: (5000)

- 2 spinups @ 25,000 years each $(50,000)$

- 4x250 year carbon dioxide increase scenarios (1000)

CPU hrs in: FY01 (220K), FY02 (4K), FY03 (0)

- Develop a better understanding of the sources and magnitude of variability in the terrestrial component of the carbon cycle.

Model System Subset: CCM3 with IBIS terrestrial biosphere Resolution and Forcing: T42, prescribed $20^{\text {th }}$ century SSTs Status and Ready Date: In process now TeraCluster CPU hrs per sim year. 36

Runs (total length in years):

- Testing, De-bugging, Tuning: (1000)

- 8 ensemble 40-yr runs with non-dynamic vegetation, time-varying SSTs (320)

- 8 ensemble 40-yr runs with non-dynamic vegetation, climatological SSTs (320) 
CPU hrs in: FYO1 (59K), FY02( 0 ), FY03(O)

- Simulate changes in the ocean carbon sink resulting from anthropogenic climate change in the $21^{\text {st }}$ century and beyond.

Model System Subset: PCM-2 with Ocean Carbon Cycle Model

Resolution and Forcing: T42 atmosphere, 2/3 degree ocean

Status and Ready Date: Both models ready now. Accelerated spinup method under development. Ready to start testing in late FY01.

TeraCluster CPU hrs per sim year: 86

Runs (total length in years):

- Testing, De-bugging, Tuning: (100)

- Spinup (2000)

- Various carbon dioxide increase scenarios (2500)

CPU hrs in: FY01(181K), FY02(172K), FY03( 43K)

- Make initial estimates of the climatic effects of fossil-fuel aerosols (FFA) on future climate.

Model System Subset: CCM3 with IMPACT-FFA

Resolution and Forcing: T42, mixed layer ocean

Status and Ready Date: Requires further development of the IMPACT-FFA model.

Requires finishing the interactive coupling between CCM3 and IMPACT. Ready on 1

October 2001.

TeraCluster CPU hrs per sim year. 72

Runs (total length in years):

- Testing, De-bugging, Tuning: (300)

- Spinups (100)

- $3 \times 200$ year runs for $20^{\text {th }}-21^{\text {st }}$ century control and FFA effects (600)

CPU hrs in: FY01 (10K), FYO (62K), FY03(0)

- Simulate possible changes in the terrestrial carbon cycle resulting from interactive climate and dynamic vegetation effects in the $21^{\text {st }}$ century and beyond.

Model System Subset: PCM-2 with IBIS terrestrial biosphere model

Resolution and Forcing: T42 atmosphere, 2/3 degree ocean

Status and Ready Date: Awaiting development of distributed memory parallel version of IBIS in late FY01. Then coupling to PCM-2 will be required.

TeraCluster CPU hrs per sim year. 86

Runs (total length in years):

- Testing, De-bugging, Tuning: (300) 
- Spinups (1000)

- Various carbon dioxide increase scenarios (2500)

CPU hrs in: FY01 ( 0 ), FY02 (176K), FY03 (151K)

- Simulate the effects of fossil fuel aerosol scenarios on future climate.

Model System Subset: PCM-2 with IMPACT-FFA

Resolution and Forcing: T42 atmosphere, 2/3 degree ocean

Status and Ready Date: PCM-2 is ready, IMPACT-FFA needs to be developed and tested. Coupling in mid FY02

TeraCluster CPU hrs per sim year: 122

Runs (total length in years):

- Testing, De-bugging, Tuning: (200)

- Various FFA scenarios (1000)

CPU hrs in: FY01 (0), FY02 (61K), FY03 ( 85K)

- Test and run the first version of the INCCA Fully-coupled System, Version 1 (IFS v.1). This will provide comprehensive, multi-century simulations of the effects of man-made climate change on the full carbon cycle.

Model System Subset: IFS v.1 (Combines PCM-2, the LLNL Ocean Carbon Cycle Model, IBIS land biosphere model, and IMPACT-FFA aerosol chemistry model to create an integrated climate and carbon cycle modeling system.)

Resolution and Forcing: T42 atmosphere, 2/3 degree ocean

Status and Ready Date: Initial testing in late FY02, production testing in FY03

TeraCluster CPU hrs per sim year: 125

Runs (total length in years):

- Testing, De-bugging, Tuning: 200

- Spinup (1000)

- Production tests: $3 \times 300$ years

CPU hrs in: FY01(0), FY02 (25K), FY03 (238K)

Summing the seven categories above, we get:

Total TeraCluster CPU hours: $\quad$ FY02 (500K), FY03 (517K)

Total TeraCluster CPU hours per week: . FY02 (10K), FY03 (10K) 


\section{References}

A U.S. Carbon Cycle Science Plan, 1999: A report of the Carbon and Climate Working Group, Jorge L. Sarmiento and Steven C. Wofsy, co-Chairs. US Global Change Research Program. Washington, D.C. 69pp.

Caldeira, K. and P.B. Duffy, 2000: The role of the Southern Ocean in uptake and storage of anthropogenic carbon dioxide, Science, 287, 620-622.

Chuang, C. C., K. E. Grant, and J. E. Penner, 1999: Modeling black carbon effect on radiative properties of clouds in a global climate model, Proceedings of the 9th ARM Science Team Meeting, in press.

Delire C. and J.A. Foley, Evaluating the Performance of a Land Surface / Ecosystem Model with Biophysical Measurements from Contrasting Environments, Journal of Geophysical Research, vol 104, D14, 16895-16909, 1999.

Duffy, P.B., and K. Caldeira, Sensitivity of Simulated Salinity in a Three-dimensional Ocean Model to Upper-Ocean Transport of Salt From Sea-Ice Formation, Geophys. Res. Lett. , 24, 1323-1326, 1997.

Dignon J., 2001: Historic $\mathrm{SO}_{2}$ emissions from fossil fuel combustion-Potential for climate change, Atmos. Environ., submitted.

Foley, J.A., 1995: An equilibrium model of the terrestrial carbon budget. Tellus 47B, 310319.

Foley, J.A., I.C. Prentice, N. Ramankutty, S. Levis, D. Pollard, S. Stich and A. Haxeltine, 1996: An integrated biosphere model of land surface processes, terrestrial carbon balance, and vegetation dynamics. Glolal Biogeochemical Cycles, 10, 603-628.

Foley, J.A., S. Levis, I.C. Prentice, D. Pollard, and S.L. Thompson, 1998: Coupling models of climate and vegetation. Global Change Biology, 4, 561-579.

Houghton, J.T., L.G. Meira Filho, B.A. Callandar, N. Harris, A. Kattenberg, and M. K. (Eds.), 1996. Climate Change 1995, The Science of Climate Change. Intergovernmental Panel on Climate Change, Cambridge University Press, Cambridge (UK).

Jacobson, M.A., 1995: Computation of global photochemistry with SMVGEAR II, Atmos. Environ., 29A, 2541-2546.

Kucharik, C.J., J.A. Foley, C. Delire, V.A. Fisher, M.T. Coe, J. D. Lenters, C. Young-Molling, N. Ramankutty, J.M. Norman, and S.T. Gower, Testing the performance of a dynamic Global Ecosystem Model: Water balance, carbon balance, and vegetation structure, Global Biogeochemical Cycles, 14(3), pp 795-825, 2000.

Lenters, J.D., M.T. Coe, and J.A. Foley (2000). Surface water balance of the continental United States, 1963-1995: Regional evaluation of a terrestrial biosphere model and the NCEP/NCAR reanalysis. Journal of Geophysical Research (Atmospheres) 105 (D17), 22,393-22,425., 2000.

Liousse, C., J. E. Penner, C. Chuang, J. J. Walton, H. Eddleman, and H. Cachier, 1996, Modeling carbonaceous aerosols, J. Geophys. Res., 101, 19,411-19,432.

Penner, J. E., C. C. Chuang, and K. E. Grant, 1998: Climate forcing by carbonaceous and sulfate aerosols, Clim. Dyn., 14, 839-851.

Rotman, D.A., D.J. Wuebbles, and J.E. Penner, 1993: Atmospheric chemistry using massively parallel computers, 1994 AMS Fifth Annual Symposium on Global Change Studies.

Thompson, S.L. and Pollard, D., 1995: A global climate model (GENESIS) with a LandSurface-Transfer Scheme (LSX). Part 1: Present climate simulation. J. Climate, 8 , 732--761.

Thompson, S.L and B. Govindasamy, 2000: Interannual variability of the carbon cycle in a coupled model of climate and the terrestrial biosphere. Presented at the American Geophsyical Union Annual Meeting, San Francisco, 16 December 2000. 


\section{List of Acronyms}

ACPI: Accelerated Climate Prediction Initiative (DOE program)

ASD: Atmospheric Science Division of the E\&E Directorate of LLNL

CASC: Center for Applied Scientific Computing (LLNL)

CCM3: NCAR Community Climate Model version 3, an atmospheric GCM.

CSM: Climate System Model (NCAR developed)

DOCS: DOE Ocean Carbon Sequestration center (joint between LLNL and LBNL)

DOE: Department of Energy

E\&E: Energy and Environment Directorate of LLNL

FFA: Fossil Fuel Aerosol (both sulfate and sooty particulates from burning fossil fuels)

GCM: General Circulation Model (refers to atmosphere or ocean)

GENESIS: Global Environmental and Ecological Simulation of Interactive Systems (NCAR)

IBIS: Integrated Biosphere Simulator (U. Wisconsin developed model)

IMPACT: Integrated Massively Parallel Atmospheric Chemical Transport (LLNL developed)

IMPACT-FFA: Special version of IMPACT with simplified chemistry relevant to FFAs

INCCA: INtegrated Climate and CArbon

LANL: Los Alamos National Laboratory

LBNL: Lawrence Berkeley National Laboratory

LLNL: Lawrence Livermore National Laboratory

MPP: Massively Parallel Processor

NCAR: National Center for Atmospheric Research

NERSC: National Energy Research Supercomputing Center

PCM-2: Parallel Climate Model 2 (NCAR-DOE developed coupled atmosphere-ocean model)

PCMDI: Program for Climate Model-Data Intercomparison (LLNL E\&ES)

POP: Parallel Ocean Program (LANL developed ocean circulation model)

SI: Strategic Initiative

SST: Sea Surface Temperature

T42: Indicates an atmospheric spatial resolution of about $280 \mathrm{~km}$ grid spacing.

tc2k: TeraCluster 2000. Livermore Computing's large Compaq MPP machine

USGCRP: US Global Change Research Program 


\title{
14. Vitae
}

\author{
Curriculum Vita for
}

Starley L.Thompson

\section{PRESENT POSITION:}

Physicist

Climate and Carbon Cycle Modeling Group

Atmospheric Science Division

Lawrence Livermore National Laboratory

7000 East Avenue, L-103

Livermore, CA 94550-9234

Voice: $925-423-9923$

Fax: 925-422-6388

email: thompson59@Ilni.gov

PERSONAL: Citizenship: U.S.A.

PROFESSIONAL MEMBERSHIPS:

American Geophysical Union

American Association for the Advancement of Science

\section{EDUCATION:}

Ph.D. 1983, University of Washington, Atmospheric Sciences.

M.S. 1977, Texas A\&M University, Meteorology.

B.S. 1976, Texas A\&M University, Meteorology.

\section{PREVIOUS RESEARCH EXPERIENCE:}

Scientist III and Head of the Interdisciplinary Climate Systems Section, Climate and Global Dynamics Division, National Center for Atmopsheric Research.

\section{HONORS:}

- Nominated for the NCAR Outstanding Performance in Education Award (1995)

- Placement in the ACM SIGGRAPH (Special Interest Group in Computer Graphics) Video Review for the climate model video animation "CHANGE" (1995)

- American Geophysical Union 75th Anniversary Geophysical Images Contest award winner for the video animation "Seasonal Dance." (1994)

- Graduated Summa Cum Laude, Texas A\&M University (1976)

\section{GENERAL RESEARCH INTERESTS:}

Global climate simulation, Earth system modeling, Global warming 


\section{PUBLICATIONS:}

Starley Thompson has over 60 publications in the peer-reviewed literature. A relevant subset is given here.

Bergengren, J.C., S.L. Thompson, D. Pollard and R.M. DeConto, 2001: Modeling global climate-vegetation interactions in a doubled $\mathrm{CO}_{2}$ world. Climatic Change, in press.

Schneider, S.H and S.L Thompson, 2000: A simple climate model used in economic studies of global change. In New Directions in the Economics and Integrated Assessment of Global Climate Change. DeCanio, S.J., R.B. Howarth, A.H. Sanstad, S.H. Schneider and S.L. Thompson, eds., Pew Center on Global Climate Change, $59-80$.

Foley, J.A., Levis, S., Prentice, I.C., Pollard, D. and S.L. Thompson, 1998: Couplingdynamic models of climate and vegetation. Global Change Biology, 4, 561--579.

Thompson, S.L. and Pollard, D., 1997: Greenland and Antarctic mass balances for present and doubled atmospheric CO2 from the GENESIS Version 2 global climate model. Journal of Climate, 10, 871--900.

Thompson, S.L. and Pollard, D., 1997: "Computational aspects of the GENESIS Earth systems modeling project", In SIAM Procedings of Next Generation of Environmental Models and Computational Methods Workshop, G. Delic and M.F. Wheeler eds., ISBN 0-89871-378-1, 13--20.

Thompson, S.L. and Pollard, D., 1995: A global climate model (GENESIS) with a LandSurface-Transfer Scheme (LSX). Part 1: Present climate simulation. J. Climate, 8, 732--761.

Thompson, S.L. and Pollard, D., 1995: A global climate model (GENESIS) with a LandSurface-Transfer Scheme (LSX). Part 2: CO2 sensitivity. J. Climate, 8, 1104-1121.

Pollard, D. and Thompson, S.L., 1994: Sea-ice dynamics and $\mathrm{CO}_{2}$ sensitivity in a global climate model. Atmosphere--Ocean, 32, 449--467.

Bonan, G.B., Pollard, D. and Thompson, S.L., 1992: Effects of boreal forest vegetation on global climate. Nature, 359, 716-718.

Thompson, S.L., 1985: Global interactive transport simulations of nuclear war smoke, Nature, 317, 35--39.

Thompson, S.L. and S.H. Schneider, 1982: Carbon dioxide and climate: The importance of realistic geography in estimating the transient temperature response. Science, 217, 1031--1033 
Curriculum Vita for

Ken Caldeira

\section{PRESENT POSITION:}

Co-Director, DOE Center for Research on Ocean Carbon Sequestration

Physicist/Environmental Scientist, Climate and Carbon Cycle Modeling Group

Earth and Environmental Sciences Directorate

Lawrence Livermore National Laboratory

7000 East Ave, L-103

Livermore, CA 94550

(925) 423-4191

kenc@llnl.gov

\section{PERSONAL:}

Citizenship: U.S.

\section{PROFESSIONAL MEMBERSHIPS:}

Scientific Advisory Panel, US Global Carbon Cycle Research Program $\mathrm{CO}_{2}$ Panel of Experts, UNESCO International Oceanography Commission Science Advisory Panel, AGU Biogeochemistry Section

\section{GENERAL RESEARCH INTERESTS:}

global carbon cycle; climate; numerical simulation of climate and chemistry; chemical oceanography; energy policy; marine biogeochemical cycles; ocean carbon sequestration, long-term evolution of Earth's climate and geochemical cycles

\section{PREVIOUS RESEARCH EXPERIENCE:}

Co-Director, DOE Center for Research on Ocean Carbon Sequestration (LLNL, 1999 to present) Research ocean carbon cycle; ocean carbon sequestration, numerical simulation of ocean circulation and biogeochemistry.

Physicist/Environmental Scientist (LLNL, 1995 to present) Research ocean carbon cycle, atmospheric $\mathrm{CO}_{2}$, ocean/sea-ice physics, climate, and energy systems.

Post-Doctoral Researcher (LLNL; 1993 to 1995) Research the ocean carbon cycle, atmospheric $\mathrm{CO}_{2}$ and climate.

NSF Earth Sciences Postdoctoral Fellow (Earth Systems Science Center \& Dept. of Geosciences, The Pennsylvania State University; 1991 to 1993) Role of the carbonatesilicate cycle in long-term atmospheric $\mathrm{CO}_{2}$ content and climate.

\section{EDUCATION:}

Ph.D.,1991, New York University, Atmospheric Sciences, Department of Applied Science. M:S.,1988, New York University, Atmospheric Sciences, Department of Applied Science.

B.A.,1978 Rutgers College. (Major: Philosophy. Minor: Mathematics). 


\section{PUBLICATIONS (1998 to present):}

Govindasamy, B., P.B. Duffy, and K. Caldeira, Land use changes and Northern Hemisphere cooling, Geophysical Research Letters 28, 291-294, 2001.

Caldeira, K., and P.B. Duffy, The role of the Southern Ocean in uptake and storage of anthropogenic carbon dioxide, Science, 287, 620-622, 2000.

Caldeira, K., M.I. Hoffert, and A. Jain, Simple ocean carbon cycle models, in The Carbon Cycle, T.M.L. Wigley and D.S. Schimel, eds., Cambridge University Press, Cambridge, United Kingdom, 199-211, 2000.

Govindasamy, B., and K. Caldeira, Geoengineering Earth's radiation balance to mitigate $\mathrm{CO}_{2}$-induced climate change, Geophysical Research Letters 27, 2141-2144, 2000.

Caldeira, K., and G.H. Rau, Accelerating carbonate dissolution to sequester carbon dioxide in the ocean: Geochemical implications, Geophysical Research Letters, 27, 225-228, 2000.

Duffy, P.B., and Caldeira, K.G. Sensitivity of simulated salinities in a three dimensional ocean general circulation model to vertical mixing of destabilizing surface fluxes, Climate Dynamics v. 15, 81-88, 1999.

Kerrick, D.M., and Caldeira, K., Was the Himalayan orogen a climatically-significant coupled source and sink for atmospheric $\mathrm{CO}_{2}$ during the Cenozoic? Earth and Planetary Science Letters 173, 195-203, 1999.

Rau, G.H., and Caldeira, K. Enhanced carbonate dissolution: A means of sequestering waste $\mathrm{CO}_{2}$ as ocean bicarbonate. Energy Conversion and Management 40, 1803-1813, 1999.

Caldeira, K., and R.A. Berner, The need for mass balance and feedback in the geochemical carbon cycle: Reply, Geology 26, 478-478, 1998.

Caldeira, K., and P.B. Duffy, Sensitivity of simulated CFC-11 distributions in a global ocean model to the treatment of salt rejected during sea-ice formation, Geophys. Res. Lett. 25, 1003-1006, 1998.

Caldeira, K., G.H. Rau, and P.B. Duffy, Predicted net efflux of radiocarbon from the ocean and increase in atmospheric radiocarbon content, Geophys. Res. Lett. 25, 3811-3814, 1998.

Hoffert M.I., K. Caldeira, A.K. Jain, E.F. Haites, L.D.D. Harvey, S. D. Potter, M.E. Schlesinger, S. H. Schneider, R.G. Watts, T. M. L Wigley, and D. J. Wuebbles. Energy implications of future stabilization of atmospheric $\mathrm{CO}_{2}$ content. Nature 395, 881-884, 1998.

Stephens, B.B., Keeling, R.F., Sarmiento, J., Six, K., Murnane, R., and K. Caldeira, Atmospheric oxygen as a test of ocean carbon cycle models, Global Biogeochemical Cycles 12, 213-230, 1998.

Kerrick, D.M. and K. Caldeira, Metamorphic $\mathrm{CO}_{2}$ degassing from orogenic belts, Chemical Geology 145 213-232, 1998. 
Curriculum Vita for

\section{Christine Delire}

\section{PRESENT POSITION:}

\section{Research Associate}

Center for Sustainability and the Global Environment (SAGE)

Institute for Environmental Studies

University of Wisconsin

1225 West Dayton Street

Madison, WI, 53706

Voice: $608-262-5961$

Fax: 608-265-4113

email: cldelire@facstaff.wisc.edu

\section{PERSONAL:}

Citizenship: Belgium

\section{PROFESSIONAL MEMBERSHIPS:}

American Geophysical Union

\section{EDUCATION:}

Ph.D. 1996 (Doctorat en Sciences), University of Liège (Belgium), Atmospheric Sciences. M.S. 1990 (Maîtrise), University of Liège (Belgium), Astrophysics and Geophysics B.S. 1989 (Licence en Physique), Free University of Brussels (Belgium), Physics

\section{PREVIOUS RESEARCH EXPERIENCE:}

Post-doctoral fellow at the 'Centre National de Recherches Météorologiques, MétéoFrance' (Research center of the French weather forecasting).

\section{GENERAL RESEARCH INTERESTS:}

Simulation of Climate-Vegetation interactions, Global climate simulation 


\section{PUBLICATIONS:}

Delire C., P. Behling, M. T. Coe, J. A. Foley, R. Jacob, J. Kuzbach, Z. Liu, and S. Vavrus: Simulated response of the atmosphere-ocean system to deforestation in the Indonesian Archipelago, Geophysical Research Letters, in press.

El Maayar M., D. T. Price, C. Delire, J. A. Foley, A.T. Back, and P. Bessemoulin, Validation of the Integrated Blosphere Simulator (IBIS) over Canadian deciduous and coniferous boreal forest stands, Journal of Geophysical Research, in press.

Kucharik, C.J., J.A. Foley, C. Delire, V.A. Fisher, M.T. Coe, J. D. Lenters, C. Young-Molling, N. Ramankutty, J.M. Norman, and S.T. Gower, Testing the performance of a dynamic Global Ecosystem Model: Water balance, carbon balance, and vegetation structure, Global Biogeochemical Cycles, 14(3), pp 795-825, 2000.

Dolman AJ, Dias MAS, Calvet JC, Ashby M, Tahara AS, Delire C, Kabat P. Fisch GA, Nobre CA, Meso-scale effects of tropical deforestation in Amazonia: preparatory LBA modelling studies, Annales Geophysicae- Atmosphere, hydrodspheres and space sciences, 17: (8) 1095-1110, 1999.

Delire C. et J. Foley, Evaluating the Performance of a Land Surface / Ecosystem Model with Biophysical Measurements from Contrasting Environments, Journal of Geophysical Research, 104, D14, pp 16895-16909, 1999.

François L.-M., C. Delire, P. Warnant et G. Munhoven, Modelling theGlacial-Interglacial Changes in the Continental Biosphere, Global and Planetary Change, 16-17, pp 37-52, 1998.

Delire C., J.-C. Calvet, J. Noilhan, I. Wright, A. Manzi et C. Nobre, Physical properties of Amazonian soils - A modeling study using the ABRACOS data, Journal of Geophysical Research, 102, D25, pp 3019-30133, 1997.

Calvet J-C., R. Santos-Alvalá, G. Jaubert, C. Delire, C. Nobrel. Wright, and J. Noilhan, Mapping surface parameters for mesoscale modeling in forested and deforested south-western Amazonia, Bulletin of the American Meteorological Society, 78, n. 3, 1997.

Denis C., Y. Rogister, M.Amalvict, C.Delire, A Ibrahim Denis, and G.Munhoven, Hydrostatic flattening, core structure, and translational mode of the inner core', Physics of the Earth and Planetary Interiors, 99, pp 195-206, 1997.

Delire C. et J-C. Gerard, A numerical study of the influence of the diurnal cycle on the surface energy and water budget, Journal of Geophysical Research, 100, D3, pp 5071-5084, 1995.

Friedlingstein P., C. Delire, J.F. Müller and J.C. Gerard, The climate induced variation of the continental biosphere: a model simulation of the Last Glacial Maximum,

Geophysical Research Letters, 19, NO. 9, 897-900, 1992. 


\section{Jane Dignon, Ph.D.}

\section{Address}

Lawrence Livermore National Laboratory

University of California

Telephone: (510) 423-2570

P.O. Box 808, L-103

Fax: (510) 423-4908

Livermore, CA 94551

e-mail: dignon@llnl.gov

\section{Education}

B.S., 1979, State University of New York at Albany, NY (Atmospheric Science)

M.S., 1982, State University of New York at Stony Brook, NY (Environmental/Mechanical Engineering)

Ph.D., 1988, State University of New York at Stony Brook, NY (Atmospheric Science/Mechanical Engineering)

Management Certificate, 1995, University of the Pacific, Stockton, CA, School of Business and Public Administration

\section{Honors or Awards}

American Men and Women in Science, Sigma Xi, Who's Who in American Science, Who's Who in American Women, New York State Regents Scholarship

\section{Research Interests}

Modeling atmospheric chemical and physical processes; development of global trace gas emissions inventories from natural and anthropogenic sources; determining the effect of emissions on ambient trace gas concentrations and climate on global and regional scales.

\section{Professional Employment}

1998-present

Physicist, Atmospheric Science Division, Lawrence Livermore National Laboratory, Livermore, CA.

1992-1998

Physicist (Term Appointment), Atmospheric Science Division, Lawrence Livermore National Laboratory, Livermore, CA.

1989-1992

Post-Doctoral Appointee, Atmospheric and Geophysical Sciences Division, Lawrence Livermore National Laboratory, Livermore, CA.

1991-present

Chief Financial Officer, Golden International, Livermore, CA.

1989

Adjunct Professor, Helsinki University of Technology, Otaniemi, Finland.

Research Associate, State University of New York at Stony Brook, Institute for Earth and Planetary Atmospheres, Stony Brook, NY

\section{Professional Affiliations}

American Geophysical Union American Meteorological Society Air and Waste Management Association IGAC - GEIA 


\section{Publications since 1997}

Dignon J., 2001: Historic $\mathrm{SO}_{2}$ emissions from fossil fuel combustion-Potential for climate change, Atmospheric Environment, submitted.

Dignon, J., 1998: Foreign Trip Report: International Workshop on Global Emissions Inventory Activity and IPCC Expert Meeting for the Assessment of Emission Inventory Quality, Bilthoven, Netherlands, November, 1997. UASG-98-1.

Dignon, J. 1997: Historic global $\mathrm{SO}_{2}$ emissions inventory for climate detection studies, FY97 Report to NOAA. UCRL-ID-125610

Dignon, J. K. Grant, A. Grossman, D. Wuebbles, G. Brasseur, S. Madronich, T. Huang, J. Chang, B. Lott, 1997: GRI Methane Chemistry Review, UCRL-CONF-970284.

Dignon, J., M.A.K. Khalil, T. Ando, C.A.M. Brenninkmeijer, C. Brühl, R. Chatfield, C. Granier, M. Kanakidou, G. King, S. King, K. Law, T. Röckmann, D. Stedman, Y. Yung, and O. Zafiriou, 1998: Carbon Monoxide Sources and Sinks, EPA Report.

Dignon, J., C.S. Atherton, H.E. Eddleman, J.E. Penner, J.J. Walton and A.S. Grossmann, 1998: Quantifying Magnitudes and Distributions of CO Sources, Chemosphere., in progress.

Jacob, D., M. Prather, P. Rasch, R. Shia, Y. Balkanski, S. Beagley, D. Bergmann, W. Blackshear, M. Brown, M. Chiba, M., Chipperfield, J. deGrandpre, J. Dignon, J. Feichter, C. Genthon, W. Grose, P. Kasibhatla, I. Kohler, M. Kritz, K. Law, J. Penner, M. Ramonet, C. Reeves, D. Rotman, D. Stockwell, P. Van Velthoven, G. Verver, O. Wild, H. Yang, and P. Zimmerman, 1997: Evaluation and intercomparison of global atmospheric tracer models using $222 \mathrm{Rn}$ and other short-lived tracers, Journal of Geophysical Research, 102, 5953-5970.

Wuebbles, D.J., J. Edmonds, J. Dignon, W. Emanuel, D. Fisher, R. Gammon, R. Hangebrauck, R. Harriss, M.A.K. Khalil, J. Spence, and T. Thompson, 1997: Emissions and budgets of radiatively important atmospheric constituents, The Engineering Response to Global Climate Change: A workshop for Planning a Research and Development Agenda, R. Watts, ed., pp. 67-135, CRC Press, Boca Raton, FL.

\section{Selected Abstracts and Presentations since 1997}

Dignon, J., C Atherton, D. Bergmann, C. Chuang, P. Connelf, D. Rotman, and J. Tannahill, 2000: Analysis of the non-linear effects of the diurnal cycle on the sulfur cycle. American Geophysical Union (AGU) Fall Meeting, San Francisco, CA, December 2000.

Dignon, J. 1997: Sulfur emissions from fossil fuel combustion, American Chemistry Society Meeting, Geochemistry Division, Las Vegas, NV, September 8-11, 1997. UCRL-JC127303-ABS.

Dignon, J. 1997: Historic Emissions of $\mathrm{SO}_{2}$, Eighth International Workshop of the Global Emissions Inventory Activity (GEIA), (Invited) Bilthoven, Netherlands, November, 1997.

Dignon, J., C.S. Atherton, H.E. Eddleman, J.,E. Penner, and J.J. Walton, 1997: Quantifying the magnitudes and distributions of carbon monoxide sources using a threedimensional chemical tracer model, International Conference on Atmospheric Carbon Monoxide and its Environmental Effects, Portland, OR, December, 1997. UCRL-JC-128835-ABS.

Dignon, J., H.E. Eddleman, C.S. Atherton, J.E. Penner, J.J. Walton, 1997: 3-D global chemical tracer model analysis of carbon monoxide emissions, American Geophysical Union (AGU) Fall Meeting, San Francisco, CA, December, 1997. UCRLJC-128341-ABS.

Dignon J. and B. D. Santer, 1998: Analysis of anthropogenic $\mathrm{SO}_{2}$ emissions and their impact on regional climate, Joint International Symposium on Global Atmospheric Chemistry and Global Pollution (CACGP), Seattle WA, August 19-25, 1998. UCRL-JC130356-ABS.

Dignon, J. and S.D. Goldenberg, 1998: INA Leadership Seminar, (Invited) San Jose, CA, March 21-22, 1998. 


\section{Curriculum Vita for}

Philip B. Duffy

\section{PRESENT POSITION:}

Group Leader, Climate and Carbon Cycle Modeling Group

Atmospheric Science Division,

Lawrence Livermore National Lab.

University of California

P.O. Box 808, L-103

Livermore, CA 94550

Telephone:(925) 422-3722

Fax:(925) 422-6388

email:pduffy@IInl.gov

duffy2@IInl.gov

PERSONAL: Citizenship: U.S.

\section{EDUCATION:}

January 1979, A.B., Magna Cum Laude, Harvard University, (Astronomy and Astrophysics)

June 1981, M.S., Stanford University, Palo Alto, Ca. Applied Physics (Astrophysics)

June 1986, Ph.D., Stanford University, Palo Alto, Ca. Applied Physics (Astrophysics)

\section{PREVIOUS RESEARCH EXPERIENCE:}

Sept., 1993-Present:

Atmospheric Science Division, Lawrence Livermore National Laboratory (LLNL)

April 1989-Sept., 1993:

Computational Physics Group, Nuclear Test Division, LLNL

July 1986-April 1989:

Strategic Defensive System Studies Group, LLNL

\section{GENERAL RESEARCH INTERESTS:}

The role of oceans in climate and climate change; numerical modeling of oceans; natural climate variability; the ocean carbon cycle.

\section{PUBLICATIONS AND OTHER PAPERS:}

P. B. Duffy, C. Doutriaux, I. Fodor, and B. Santer, Effect of Missing Data on Estimates of Near-Surface Temperature Change Since 1900, J. Climate, accepted.

P. B. Duffy, M.E. Wickett, and K. Caldeira, Effect of horizontal grid resolution on the nearequilibrium solution of a giobal ocean/sea ice model, J. Geophys. Res., submitted.

M. E. Wickett, P.B. Duffy, and G. Rodrigue, A reduced grid for a parallel global ocean general circulation model, Ocean Modelling, in press.

B.J. McAvaney et al, "Model Evaluation", in Climate Change: The Scientific Basis; IPCC Third Assessment Report, Cambridge University Press, in press.

P. B. Duffy, M. Eby, and A.J. Weaver, Climate Model Simulations of Effects of Increased Atmospheric $\mathrm{CO}_{2}$ and Loss of Sea Ice on Ocean Salinity and Tracer Uptake, J. Climate, in press. 
B. Govindasamy, P. B. Duffy, and K. Caldeira, Land Use Changes and Northern Hemisphere Cooling, Geophys. Res. Lett, 28, 291-294, 2001.

T. Guilderson, K. Caldeira, and P. Duffy, Radiocarbon as a diagnostic tracer in ocean and carbon cycle modeling, Global Biogeochemical Cycles, 14, 887-902, 2000.

M.I. Hoffert, K. Caldeira, C. Covey, P.B. Duffy, B. Santer, Solar variability and the Earth's climate, Nature, 401, 764-764, 1999.

J. Bell, P. B. Duffy, C. Covey, and L. Sloan, Analysis of Temperature Variability in Sixteen Climate Model Simulations, Geophysical Research Letters, 27, 261-264, 2000.

P. B. Duffy, J. Bell; C. Covey, and L. Sloan, Effect of flux adjustments on temperature variability in coupled models, Geophysical Research Letters., 27, 763-766, 2000.

K. Caldeira and P.B. Duffy, The role of the Southern Ocean in uptake and storage of anthropogenic carbon dioxide, Science, 287, 620-622, 2000.

A.J. Weaver, P. B. Duffy, M. Eby, and E.C. Wiebe, On the evaluation of ocean and climate models using present-day forcing, Atmosphere-Ocean, 38, 271-201, 2000.

P. B. Duffy, M. Eby, and A.J. Weaver, Effects of Sinking of Salt Rejected During Formation of Sea Ice on Results of a Global Ocean-Atmosphere-Sea Ice Climate Model, Geophys. Res. Lett., 26, 1739-1742, 1999.

P. B. Duffy and K. Caldeira, Sensitivity of Simulated Salinities in a Three-Dimensional Ocean General Circulation Model to Vertical Mixing of Destabilizing Surface Fluxes, Climate Dynamics, 15, 81-88, 1999.

B. Govindasamy, M. F. Wehner, C. R. Mechoso, and P. B. Duffy, The Influence of a Land Surface Scheme on Simulated Climate by LLNL/UCLA AGCM, Global and Planetary Change, 20, 67-86, 1999.

K. Caldeira, G. H. Rau, and P. B. Duffy, Predicted oceanic degassing of radiocarbon and increase in atmospheric radiocarbon content, Geophys. Res. Lett., 25, 3811-3814, 1998.

K. Caldeira, and P. B. Duffy, Sensitivity of simulated CFC-11 distributions in a global ocean model to the treatment of salt rejected during sea-ice formation, Geophys. Res. Lett, 25, 1003-1006, 1998.

Wehner, M.F., P.G. Eltgroth, A.A. Mirin, P.B. Duffy, K.G. Caldeira, J.H. Bolstad, H. Wang, C.M. Matarazzo, U.E. Creach, 1997, Comprehensive Climate System Modeling on Massively Paraliel Computers, in Mission Earth: Modeling and Simulation for a Sustainable Global System, edited by M.G. Clymer and C. R. Mechoso, the Society for Computer Simulation International, 37-42, 1998.

P. B. Duffy, and K. Caldeira, Sensitivity of Simulated Salinity in a Three-dimensional Ocean Model to Upper-Ocean Transport of Salt From Sea-Ice Formation, Geophys. Res. Lett. , 24, 1323-1326, 1997.

P. B. Duffy, K. Caldeira, J. Selvaggi, and M. Hoffert, Effect of Subgrid Scale Mixing Parameterizations on Simulated Distributions of Natural ${ }^{14} \mathrm{C}$, Temperature, and Salinity in a Three-Dimensional Ocean General Circulation Model, J. Phys. Oceanogr, 27, 498-523, 1997.

G. Perry. P. B. Duffy, and N. Miller, An Extended Dataset of River Discharges for Validation of Climate Models, J. Geophys. Res., 101, 21,339-21,349, 1996.

P. B. Duffy, D. Eliason, A. J. Bourgeois, and C. Covey, Simulation of Bomb Radiocarbon in Two Ocean General Circulation Models, J. Geophys. Research, 100, 22,54522,565, 1995.

P. B. Duffy, and K. Caldeira, A Three-Dimensional Model Calculation of Ocean Uptake of Bomb ${ }^{14} \mathrm{C}$ and Implications for the Global Budget of Bomb ${ }^{14} \mathrm{C}$, Global Biogeochemical Cycles., 9, 373-375, 1995.

P. B. Duffy, P. Eltgroth, A. J. Bourgeois, and K. Caldeira, Effect of Improved Subgrid Scale Transport of Tracers on Uptake of Bomb Radiocarbon in the GFDL Ocean General Circulation Model, Geophysical Review Letters, 22, 1065-1068, 1995. 
Curriculum Vita

Jonathan A. Foley

Center for Sustainability and the Global Environment (SAGE)

Institute for Environmental Studies

University of Wisconsin

1225 West Dayton Street

Madison, Wisconsin 53706 United States

(608) 265-5144 (phone)

(608) 265-4113 (fax)

jfoley@facstaff.wisc.edu

sage.aos.wisc.edu (home page)

\section{Research Interests}

Interactions between ecological, hydrological, and atmospheric processes; applications of numerical modeling and remote sensing to natural resource studies; biogeochemical cycles of water and carbon; effects of land use on natural and managed ecosystems and hydrological systems; environmental change, natural resources and human systems

\section{Current Employment}

University of Wisconsin, Institute for Environmental Studies (IES) \& Department of Atmospheric and Oceanic Sciences, 1993 - present:

- Director: IES -Center for Sustainability and the Global Environment (SAGE)

- Reid A. Bryson Distinguished Professor of Climate People \& Environment

- Associate Professor of Environmental Studies, Associate Professor of Atmospheric Sciences

\section{Education}

Ph.D., Atmospheric Sciences, University of Wisconsin, 1993

\section{Awards}

Ecological Society of America - Aldo Leopold Leadership Fellow (2000-2001)

University of Wisconsin - Romnes Faculty Fellowship (2000-2001), Vilas Associate Award (1999-2001)

NASA - Presidential Early Career Award for Scientists and Engineers (1997 - 2002)

National Science Foundation - Faculty Career Development Award (1995 - 1999)

University of Wisconsin - R.A. Bryson Distinguished Professorship (1993 - present)

National Science Foundation - Graduate Fellowship (1990-1993)

\section{Selected Publications}

Coe, M.T. and J.A. Foley. Human and natural impacts on the water resources of the Lake Chad basin. submitted to Journal of Geophysical Research (Atmospheres).

Foley, J.A., S. Levis, M.H. Costa, W. Cramer, and D. Pollard: Incorporating dynamic vegetation cover within global climate models, Ecological Applications, in press.

Kucharik, C.J., J.A. Foley, C. Delire, V.A. Fisher, M.T. Coe, S.T. Gower, J. Lenters, C. Molling, J.M. Norman, N. Ramankutty: The IBIS-2 dynamic global biosphere model: Model formulation and evaluation, Global Biogeochemical Cycles., in press

Costa, M.H. and J.A. Foley, 2000: Combined effects of deforestation and doubled atmospheric $\mathrm{CO}_{2}$ concentrations on the climate of Amazonia. Journal of Climate. 13(1), 18-34. 
Ramankutty, N., and J.A. Foley, 1999: Estimating historical changes in global land cover: croplands from 1700 to 1992. Global Biogeochemical Cycles 13(4), 997-1027.

Ramankutty, N., and J.A. Foley, 1999: Estimating historical changes in land cover: North American croplands from 1850 to 1992. Global Ecology and Biogeography 8, 381396.

Foley, J.A., S. Levis, I.C. Prentice, D. Pollard, and S.L. Thompson, 1998: Coupling dynamic models of climate and vegetation, Global Change Biology, 4, 561-579.

Foley, J.A., I.C. Prentice, N. Ramankutty, S. Levis, D. Pollard, S. Sitch and A. Haxeltine, 1996: An integrated biosphere model of land surface processes, terrestrial carbon balance, and vegetation dynamics, Global Biogeochemical Cycles, 10, 603-628. 
Curriculum Vita for

\section{Bala Govindasamy}

\section{PRESENT POSITION:}

Physicist

Climate and Carbon Cycle Modeling Group

Atmospheric Science Division

Lawrence Livermore National Laboratory

7000 East Avenue, L-103

Livermore, CA 94550-9234

Voice: $925-423-0771$

Fax: $925-422-6388$

email: bala@llnl.gov

\section{PERSONAL:}

Citizenship: India

PROFESSIONAL MEMBERSHIPS:

American Geophysical Union

\section{EDUCATION:}

Ph.D. 1994, McGill University, Canada, Atmospheric and Oceanic Sciences.

M.S. 1988, University of Poona, India, Physics.

B.S. 1976, Madras University, India, Physics.

\section{PREVIOUS RESEARCH EXPERIENCE:}

Dec. 1996 to Sept. 1998: Staff Research Associate, UCLAVLLNL.

Sept. 1994 to Nov. 1996: Visiting Scientist, GFDLPrinceton University

\section{HONORS:}

- McGill-CIDA (Canadian International Development Agency) Fellowship, 1990-1994.

- TIFR Scholarship, 1986-1988.

- Government of India Merit Scholarship, 1981-1986.

- Merit Scholarship, 1979-1981.

\section{GENERAL RESEARCH INTERESTS:}

Atmospheric General Circulation Modeling (AGCM), Coupled Ocean-Atmosphere-Land system modeling, Regional and global climate change studies, High Performance computing. 


\section{PUBLICATIONS:}

Govindasamy, B., K. E. Taylor, P. B. Duffy, B. J. Santer, A. S. Grossman, and K. E. Grant, 2001: Limitations of the equivalent $\mathrm{CO} 2$ approximation in climate change simulations (submitted to J. Geophys. Res.).

Bala Govindasamy, Phil Duffy, and Ken Caldeira, 2001: Land use change and Northern Hemisphere cooling, Geophys. Res. Lett., 28 , No. 2, p. 291.

Govindasamy, B., and Caldeira, K., 2000: Geoengineering Earth's radiation balance to mitigate $\mathrm{CO}_{2}$-induced climate change, Geophys. Res. Lett., 27 , No. 14 , p. 2141

Teller, E., K. Caldeira, G. Canavan, B. Govindasamy, A. Grossman, R. Hyde, M.Ishikawa, A. Ledebuhr, C. Leith, C. Molenkamp, J. Nuckolls, and L. Wood, 1999: Long-range weather prediction and prevention of climate catastrophes: A status report. 24th International Seminar on Planetary Emergencies, Erice, Italy, 19-24 August 1999.

B.Govindasamy, M.F.Wehner, C.R.Mechoso, and P.B.Duffy, 1999: The influence of a SoilVegetation-Atmosphere Transfer scheme on the simulated climate of LLNL/UCLA AGCM. Global and Planetary Change, 20, 67-86.

B.Govindasamy, and S.T.Garner, 1997: The equilibration of short baroclinic waves. J. Atmos Sci., 54, 2850-2871.

G.Balasubramanian, and S.T.Garner, 1997: The role of eddy momentum fluxes in shaping the lifecycle of a Baroclinic wave. J. Atmos. Sci., 54, 510-533.

G.Balasubramanian, and S.T.Garner, 1996: The role of eddy momentum fluxes in shaping the lifecycle of a Baroclinic wave. Joint AMS-RMS 7th conference on mesoscale processes, Reading, United Kingdom.

G.Balasubramanian, and M.K.Yau, 1996: The lifecycle of a simulated marine cyclone: Energetics and PV Diagnostics. J. Atmos. Sci., 53, 639-563.

G.Balasubramanian, and M.K.Yau, 1995: Explosive marine cyclogenesis in a three layer model with a representation of slantwise convection: A sensitivity study. J. Atmos. Sci., 52, 533-550.

G.Balasubramanian, and M.K.Yau, 1994a: Baroclinic instability in a two-layer model with parameterized slantwise convection. J. Atmos. Sci., 51, 674-701.

G.Balasubramanian, and M.K.Yau, 1994b: Effects of convection on a simulated marine cyclone. J. Atmos. Sci., 51, 2397-2417.

G.Balasubramanian, and M.K.Yau, 1994c: An evaluation of the interaction between slantwise convection and marine cyclogenesis. Preprint volume of Cyclone symposium, Bergen, Norway. 


\section{Curriculum Vita for \\ Jose L. Milovich}

\section{PRESENT POSITION:}

Physicist/Computational Scientist

Climate and Carbon Cycle Modeling Group

Atmospheric Science Division, Lawrence Livermore National Laboratory.

Voice: $925-423-6689$

Fax: $925-422-6388$

email:milovich1@!lnl.gov

\section{PERSONAL:}

Citizenship: U.S.A.

PROFESSIONAL MEMBERSHIPS:

American Physical Society

\section{EDUCATION:}

Ph.D. PHYSICS, 1987, University of California at Los Angeles, Physics Department M.S., PHYSICS, 1982, University of California at Los Angeles, Physics Department

B.S., PHYSICS, 1979, University of Cuyo, Instituto de Fisica Balseiro, San Carlos the Bariloche, Pcia de Rio Negro, Argentina.

\section{PREVIOUS RESEARCH EXPERIENCE:}

Physicist/Computational Scientist (CASC, LLNL, 1999 to present): Research on carbon cycle and carbon sequestration.

Physicist/Computational Scientist (CASC, LLNL, 1995 to 1998): Research on 3D matterradiation transport in Inertial Confinement Fusion.

Physicist/Computational Scientist (NERSC, LLNL, 1992 to 1994): Research on Tokamak 3D turbulence.

Physicist/Computational Scientist (NERSC, LLNL, 1991 to 1992): Parallelization of scientific applications in distributed and shared-memory architectures.

Post-Doctoral Researcher (LLNL; 1989 to 1991): Research on Tokamak edge transport phenomena.

Post-Doctoral Researcher (Columbia University; 1987 to 1989): Research on MHD theory of moving plasmas.

\section{GENERAL RESEARCH INTERESTS:}

Global carbon cycle; climate; numerical simulation of climate; physical oceanography; marine biogeochemical cycles. 


\section{PUBLICATIONS:}

J. L. Milovich, B. D. Fried and G. J. Morales, Growth Rates of Parametric Instabilities Driven by Two Pumps, Phys. Fluids 27, 1647 (1984).

P. Chen and J. L. Milovich. An Explicit Solution for Static Unbounded Helical Dynamos, Geophys. Astrophys. Fluid Dyn. 30, 343 (1984).

A. Bhattacharjee, R. lacono, J. L. Milovich and C. Paranicas Ballooning Stability Of Axisymmetric Plasmas With Sheared Equilibrium Flows.; Physics Of Fluids BPlasma Physics 1, 2207 (1989).

T. Sen and J. L. Milovich, Geometric Phases in 2-Level Atoms Excited by Pulses Propagating without Loss, Phys. Rev. A 45, 1371 (1992).

R.J. Goldston, et al., Burning Plasma Experiment Special, Fusion Technology 21, 1039 (1992).

T.D. Rognlien, J.L. Milovich, M.E. Rensink and G.D. Porter, A Fully Implicit, Time Dependent 2-D Fluid Code for Modeling Tokamak Edge Plasmas, Journal of Nuclear materials 196, 347 (1992).

T.D. Rognlien, J.L. Milovich, M.E. Rensink and T.B. Kaiser, Simulation of Tokamak Divertor Plasmas Including Cross-Field Drifts, Contributions to Plasma Physics 32, 485 (1992).

D.N. Hill, B. Braams, J. Haines, J.L. Milovich, et al., Boundary Physics, Fusion Technology 21,1256 (1992).

J.L. Milovich, T.D. Rognlien, M.E. Rensink and T.B. Kaiser, A Fully Implicit Code to Model Tokamak Plasma Edge Transport, presented to the fourth International Conference in Computational Physics Proceedings, Praha August 24-28, 1992.

R.E. Waltz, G.D. Kerbel, and J. L. Milovich, Toroidal gyro-Landau fluid model turbulence simulations in a nonlinear ballooning mode representation with radial modes, Phys. Plasmas 1 (7), July 1994.

Waltz R.E., Kerbel G.D; J. Milovich.; Hammett G.W., Advances in the simulation of toroidal gyro-landau fluid model turbulence, Physics of Plasmas 2, 2408 (1995).

Kerbel, G.D., Pierce, T., Milovich, J.L., Shumaker, D.E., and others. Interactive scientific exploration of gyrofluid Tokamak turbulence, Int. Journal of Supercomputing Applications and High performance computing 10, 182-198, (1996).

D.S. Kershaw, M.K. Prasad, M.J. Shaw and J.L. Milovich, 3D Unstructured Mesh ALE Hydrodynamics with the Upwind Discontinuous Finite Element Method, Comp. Meth. in Appl. Mech. Eng. 158, 81 (1998).

A.I. Shestakov and J.L. Milovich, Parallelization of an Unstructured Grid, Hydrodynamic Diffusion Code, Proccedings of 5th International Symposium, IRREGULAR '98, Berkeley, CA, August 9-11, 1998, appear in Solving Irregularly Structured Problems in Parallel, Lecture Nodes in Computer Science 1457, 182 Springer 1998.

A.I. Shestakov, J.L. Milovich and D.S. Kershaw, Parallelization of an Unstructured-Grid, Laser Fusion Design Code, Applications on Advanced Architecture Computers, SIAM NEWS, News Journal of the Society for Industrial and Applied Mathematics, 32, 6, April 1999.

A.I. Shestakov, M.K. Prasad, J.L. Milovich, N.A. Gentile, J.F. Painter and G. Furnish, The Radiation-Hydrodynamic ICF3D Code, Computer Methods in Applied Mechanics and Engineering 187, 181-200, (2000). 
Porter, D.H., P.R. Woodward, R.H. Cohen, W.P. Dannevik, A.M. Dimits, D.E. Eliason and A.A. Mirin, "Scaling of Back Scatter in a Richtmyer-Meshkov Mixing Layer," American Physical Society Meeting, Minneapolis (2000). Also available as Lawrence Livermore National Laboratory technical report UCRL-JC-136778.

Woodward, P.R., S.E. Anderson, D.H. Porter, D. Dinge, I. Sytine, T. Ruwart, M. Jacobs, R.H. Cohen, B.C. Curtis, W.P. Dannevik, A.M. Dimits, D.E. Eliason, A.A. Mirin, K. Winkler and S. Hodson, "Exploiting the Power of DSM and SMP Clusters for Parallel CFD," Parallel CFD'99, Williamsburg (1999). Also. available as Lawrence Livermore National Laboratory technical report UCRL-JC-133693.

Mirin, A.A., R.H. Cohen, B. Curtis, W.P. Dannevik, A.M. Dimits, D.E. Eliason, T. Peyser and O. Schilling, "Simulation of Richtmyer-Meshkov Instability using the SPPM Code on the IBM SST System," Lawrence Livermore National Laboratory technical report UCRL-MI-133186 (1999).

Woodward, P.R., S.E. Anderson, D.H. Porter, D. Dinge, I. Sytine, T. Ruwart, M. Jacobs, R.H. Cohen, B.C. Curtis, W.P. Dannevik, A.M. Dimits, D.E. Eliason, A.A. Mirin, K-H. Winkler and S. Hodson, "Harnessing the Power of the New SMP Cluster Architecture," High Performance Computing on Hewlett-Packard Systems Conference, Tromsoe, Nonway (1999). Also available as Lawrence Livermore National Laboratory technical report UCRL-JC-134547.

Dimits, A.M., R.H. Cohen, W.P. Dannevik, D.E. Eliason, B.I. Jun, A.A. Mirin, T.A. Peyser, O. Schilling, D.H. Porter and P.R. Woodward, "Mixing Rates Due to Rayleigh-Taylor Instability," APS Division of Fluid Dynamics Meeting, New Orleans (1999). Also available as Lawrence Livermore National Laboratory technical report UCRL-JC-135233.

Eliason, D.E., L. Cloutman, R.H. Cohen, W.P. Dannevik, A.M. Dimits, A.A. Mirin, T.A. Peyser, O. Schilling, D.H. Porter and P.R. Woodward, "Simulations of a Two-Scale Richtmyer-Meshkov Instability," APS Division of Fluid Dynamics Meeting, New Orleans (1999). Also available as Lawrence Livermore National Laboratory technical report UCRL-JC-135234.

Mirin, A.A., G. Sugiyama, R.M. Hodur, J.M. Schmidt and S. Chen, "Design Considerations and Performance of a Scalable Version of a Nonhydrostatic Atmospheric Model," DOD High Performance Computing Modernization Program Users Group Conf., Monterey (1999). Also available as Lawrence Livermore National Laboratory technical report UCRL-JC-133451.

Schmidt, J.M., R.M. Hodur, A.A. Mirin, G. Sugiyama and S. Chen, "Applications of the Parallel, Scalable Version of the Coupled Ocean/Atmosphere Mesoscale Prediction System (COAMPS)," DOD High Performance Computing Modernization Program Users Group Conf., Monterey (1999). Also available as Lawrence Livermore National Laboratory technical report UCRL-JC-133695.

Cohen, R.H., W.P. Dannevik, A.M. Dimits, D.E. Eliason, A.A. Mirin, T. Peyser, O. Schilling, D.H. Porter and P.R. Woodward, "Simulations of Two-Scale and Double-Shocked Richtmyer-Meshkov Instability," Seventh Int'l. Workshop on the Physics of Compressible Turbulent Mixing, St. Petersburg (1999). Also available as Lawrence Livermore National Laboratory technical report UCRL-JC-133258.

Dimits, A.M., A.W. Cook, L. Cloutman, R.H. Cohen, W.P. Dannevik, D.E. Eliason, B.I. Jun, A.A. Mirin, T.A. Peyser, O. Schilling, D.H. Porter and P.R. Woodward, "Sensitivities of Mixing Rates due to RayleighTaylor Instability," Seventh Int'. Workshop on the Physics of Compressible Turbulent Mixing, St. Petersburg (1999). Also available as Lawrence Livermore National Laboratory technical report UCRLJC-133257.

Mirin, A.A., "Performance of Large-Scale Scientific Applications on the IBM ASCI Blue-Pacific System," Ninth SIAM Conference on Parallel Processing for Scientific Computing (1999), San Antonio, TX. Also available as Lawrence Livermore National Laboratory technical report UCRL-JC-131596.

Mirin, A.A., D.E. Shumaker, and M.F. Wehner, "Efficient Filtering Techniques for Finite-Difference Atmospheric General Circulation Models on Parallel Processors," Parallel Comput. 24 (1998), p. 729. Also available as Lawrence Livermore National Laboratory technical report UCRL-JC-126640, Rev.1.

This work was performed under the auspices of the U.S. Department of Energy by the University of California, Lawrence Livermore National Laboratory under Contract No. W-7405-Eng-48. 


\section{Arthur A. Mirin}

Center for Applied Scientific Computing, L-561

Phone: (925) 422-4020

Lawrence Livermore National Laboratory

Fax: (925) 423-2993

Livermore, CA 94551

E-mail:mirin@IInI.gov

\section{Research Interests}

- Scientific computing

- High-performance computing

- Climate modeling

- Numerical hydrodynamics

\section{Education}

Ph.D. Mathematics, University of California at Berkeley, June 1974

A.B. Mathematics, University of California at Berkeley, June 1969

\section{Professional Experience}

5/96-present Computational Physicist, Center for Applied Scientific Computing, Lawrence Livermore National Laboratory (LLNL). Livermore, CA

1985-4/96 Leader, Computational Physics Group, National Energy Research Supercomputer Center, LLNL

1974-1984 Computational Physicist, National Energy Research Supercomputer Center, LLNL

1970-1974 Mathematical Programmer, Magnetic Fusion Energy Division, LLNL

1969-1970 Mathematical Programmer, Computation Division, LLNL

1975-1986 Lecturer, Department of Applied Science, University of California, Davis/Livermore

\section{Honors and Organizations}

- Gordon Bell Award for Best Performance, 1999 (coordinated the simulation that won this honor)

- Lawrence Livermore National Laboratory FY2000 Science and Technology Award

- Society for Industrial and Applied Mathematics

- American Physical Society

- American Geophysical Union

- Phi Beta Kappa academic honor society

\section{Selected Publications and Presentations}

Mirin,A.A., R.H. Cohen, B.C. Curtis, W.P. Dannevik, A.M. Dimits, M.A. Duchaineau, D.E. Eliason, D.R. Schikore, S.E. Anderson, D.H. Porter, P.R. Woodward, L.J. Shieh and S.W. White, "Accomplishing Very High Resolution Turbulence Simulations on the IBM-SP System," Tenth SIAM Conf. on Parallel Processing for Scientific Computing, Portsmouth, VA (2001). Also available as Lawrence Livermore National Laboratory technical report UCRL-JC-140051.

Mirin, A.A., R.H. Cohen, B.C. Curtis, W.P. Dannevik, A.M. Dimits, M.A. Duchaineau, D.E. Eliason, D.R. Schikore, S.E. Anderson, D.H. Porter, P.R. Woodward, L.J. Shieh and S.W. White, "Very High Resolution Simulation of Compressible Turbulence on the IBM-SP System, (Gordon Bell Award for Performance, 1999), Supercomputing 99 Conference, Portland, OR (1999). Also available as Lawrence Livermore National Laboratory technical report UCRL-JC-134237.

Mirin, A.A., "Two-Dimensional Domain Decomposition for Lin-Rood Dynamical Core," Lawrence Livermore National Laboratory technical report UCRL-VG-141586 (2000).

Rotman, D., C. Atherton, D. Bergmann, P. Cameron-Smith, C. Chuang, P. Connell, J. Dignon, A. Franz, K. Grant, A. Mirin, C. Molenkamp and J. Tannahill, "IMPACT, a coupled tropospheric/stratospheric chemistry model: Analysis and comparison of results to observations," American Geophysical Society Meeting, San.Francisco (2000). Also available as Lawrence Livermore National Laboratory technical report UCRL-JC-141685. 